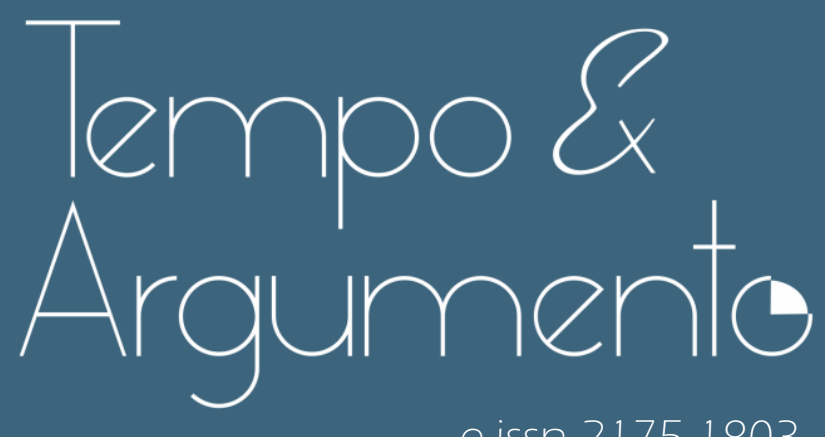

e-issn 2175-1803

El ocaso de la izquierda peronista en la Universidad de Buenos Aires: internas y debates ante la Ley Taiana 1973 - 1974

Ev Nicolás Dip

Doctor en Historia por la Facultad de Humanidades y Ciencias de la Educación de la Universidad Nacional de La Plata. Becario del Programa de Becas Postdoctorales de la Universidad Nacional Autónoma de México, en el Instituto de Investigaciones Sociales.

Ciudad de México - MÉXICO

memoria.fahce.unlp.edu.ar

nicolasdip88@gmail.com

(iD) orcid.org/0000-0001-6565-7319

Para citar este articulo:

DIP, Nicolás. El ocaso de la izquierda peronista en la Universidad de Buenos Aires: internas y debates ante la Ley Taiana 1973 - 1974. Tempo e Argumento,

Florianópolis, v. 12, n. 31, e0204, set./dez. 2020.

dof http://dx.doi.org/10.5965/2175180312312020e0204

Recebido: 09/03/2020

Aprovado: 23/08/2020 


\title{
El ocaso de la izquierda peronista en la Universidad de Buenos Aires: internas y debates ante la Ley Taiana 1973 - 1974
}

\begin{abstract}
Resumen
Este trabajo busca analizar los posicionamientos de los sectores estudiantiles, docentes e intelectuales porteños de la izquierda peronista ante la sanción de la Ley Universitaria 20.654 durante la última presidencia de Juan Domingo Perón. Agrupaciones como la Juventud Universitaria Peronista y la Agrupación Docente Universitaria Peronista, ligadas a la Juventud Peronista Regionales y Montoneros, formaron parte de un debate controvertido que terminó en la aprobación de la normativa el 14 de marzo de 1974. Ésta incorporaba parte de sus demandas sobre cómo organizar la universidad e incluso aceptaba la propuesta de la Unión Cívica Radical para que los rectores fueran elegidos por la misma comunidad académica. Pero, a la vez, otorgaba herramientas legales que permitían combatir al activismo político universitario y creaba un terreno fértil para el fortalecimiento de los sectores más reaccionarios y represivos. En todo este proceso no estuvieron ausentes las internas políticas más amplias del escenario nacional y distintas lecturas de los legados de la Reforma Universitaria de 1918. En este marco, el estudio espera demostrar que la sanción de la Ley Taiana puede entenderse como el ocaso de la izquierda peronista en la Universidad de Buenos Aires (UBA).
\end{abstract}

Palabras clave: Argentina - Historia. Izquierda (Política) - Argentina. Universidades - Argentina. Estudiantes Actividad política.

\section{The decline of the Peronist left in the Universidad de} Buenos Aires: interns and debates before the Taiana Law $1973-1974$

\begin{abstract}
This work seeks to analyze the positions of the student, teacher and intellectual sectors of the Peronist left before the sanction of University Law 20,654 during the last presidency of Juan Domingo Perón. Groups such as the Peronist University Youth and the Peronist University Teaching Group, linked to the Regional Peronist Youth and Montoneros, were part of a controversial debate that ended in the approval of the regulations on March 14, 1974. This incorporated part of their demands on how to organize the university and even accepted the proposal of the Radical Civic Union so that the rectors were chosen by the same academic community. But, at the same time, it granted legal tools that allowed to combat university political activism and created fertile ground for the strengthening of the most reactionary and repressive sectors. In all this process, the broader internal policies of the national scene and different readings of the legacies of the University Reform of 1918 were not absent. In this framework, the study hopes to demonstrate that the sanction of the Taiana Law can be understood as the decline of the Peronist left at the Universidad de Buenos Aires (UBA).
\end{abstract}

Keywords: Argentina - History. Peronist Left. University. Student Movement. 
El ocaso de la izquierda peronista en la Universidad de Buenos Aires: internas y debates ante la Ley Taiana 1973 - 1974

Nicolás Dip

\section{Introducción}

En el transcurso del siglo XX las universidades argentinas ocuparon un papel preponderante en las disputas político nacionales y a la vez resultaron atravesadas por ellas. Sin embargo, en los años sesenta la dinámica política adquirió un matiz especial. A fines de esa década y comienzos de la siguiente, numerosos universitarios participaron en la constitución de un heterogéneo conglomerado de fuerzas sociales y políticas que vinculó su oposición a la dictadura militar de Juan Carlos Onganía (1966-1970) con la posibilidad de introducir cambios más amplios, representados en la idea de revolución, socialismo y liberación. La bibliografía dedicada a la historia reciente de las universidades, los intelectuales y los movimientos estudiantiles destaca que las experiencias de peronización de estudiantes, docentes e intelectuales de la Universidad de Buenos Aires (UBA) pueden verse como un capítulo particular de la politización, radicalización y partidización del ámbito académico de esos años.

Sin embargo, esta primera aproximación debe matizarse dado que en el campo de estudios existen diferencias al respecto. A pesar de sus enfoques particulares, una buena parte de las investigaciones señalan que luego de la intervención universitaria del régimen de Onganía en 1966 se produjo una peronización de estudiantes, docentes e intelectuales porteños. ${ }^{1}$ Frente a este tipo de lecturas, análisis recientes cuestionan la existencia de dicho proceso y sostienen que antes de 1973 el peronismo nunca llegó a convertirse en una fuerza de peso en la UBA ni en otras casas de estudio del país. ${ }^{2}$ En nuestras indagaciones, señalamos que si se concibe a dicha experiencia como una adhesión masiva de universitarios al movimiento encabezado por Juan Domingo Perón, recién fue posible con el retorno del peronismo al gobierno en ese año, con la elección de Héctor Cámpora como nuevo presidente constitucional y el surgimiento de la Juventud Universitaria Peronista (JUP) y la Agrupación Docente Universitaria Peronista (ADUP), los frentes de masas universitarios de la Juventud Peronista Regionales (JP Regionales), la estructura juvenil más importante del peronismo que estaba bajo la conducción de

\footnotetext{
'Esta posición se encuentra en los estudios de Pérez Lindo (1985), Rubinich (2003), Suasnábar (2004), Buchbinder (2005), Barletta y Lenci (2000), Barletta (2001, 2002), Sarlo (2001), Barletta y Tortti, (2002), Burgos (2004), Gil (2010) y Toribio (2010).

2 Este tipo de lecturas se encuentra en los trabajos de Bonavena (2014), Califa (2015) y Millán (2013, 2019), entre otros.
} 
El ocaso de la izquierda peronista en la Universidad de Buenos Aires: internas y debates ante la Ley Taiana 1973 - 1974

Nicolás Dip

Montoneros. ${ }^{3}$ De esta manera, en estudios previos explicamos que no se trató de cualquier peronización, sino de un estilo de politización y partidización de izquierda muy específico que implicó un fenómeno doble. ${ }^{4}$ Por un lado, fue un complejo camino a través del cual estudiantes, docentes e intelectuales procedentes de sectores que habían sido opositores a los primeros gobiernos de Juan Domingo Perón (1946-1955), optaron por asumirlo como su propia identidad política, aunque desde una perspectiva revolucionaria acorde a los relatos de la época. ${ }^{5}$ Por otra parte, significó un itinerario que tejió otra forma de pensar el papel de la universidad para intentar superar viejos desencuentros y legitimar la nueva presencia del peronismo en las casas de estudio. ${ }^{6}$

La bibliografía citada anteriormente contribuyó a entender distintas aristas de la peronización en la UBA. No obstante, aún es una deuda pendiente analizar en perspectiva los posicionamientos de la JUP y la ADUP frente a la discusión, la sanción y la aplicación de la Ley Universitaria 20.654, más conocida como Ley

\footnotetext{
${ }^{3}$ Montoneros fue una agrupación guerrillera que ostentó una fuerte presencia política debido a su impactante aparición pública con la ejecución del general Pedro Eugenio Aramburu en 1970. Su protagonismo en el retorno de Perón a la Argentina en 1972 continuó durante la campaña electoral que permitió el triunfo de Cámpora al año siguiente. La organización terminó de afianzarse en 1973, cuando decidió lanzarse a la creación de una estructura federal articulada en frentes de masas, con el objetivo de robustecer a la JP Regionales. En este marco, fueron creadas la propia JUP, la Unión de Estudiantes Secundarios (UES), los Equipos Político-Técnicos, la Juventud Trabajadora Peronista, la Agrupación Evita, el Movimiento de Inquilinos Peronistas y el Movimiento de Villeros Peronistas. Todos estos espacios que se estructuraron bajo la conducción de Montoneros fueron conocidos como la Tendencia Revolucionaria del peronismo. No obstante, es necesario aclarar que dicho conglomerado no se reducía a los sectores que nombramos anteriormente, dado que era más amplio y heterogéneo. Involucraba a otras agrupaciones políticas como el Peronismo de Base y a grupos profesionales, como la Agrupación de Abogados Peronistas y el Consejo Tecnológico de Rolando García. (LENCI, 1999; SVAMPA, 2003; DE RIZ, 2003; LANUSSE, 2007; GILLESPIE, 2008; BERNETTI 2011; BARTOLETTI, 2011; PERDÍA, 2013; GONZÁLEZ CANOSA, 2014).

4 En relación a nuestras investigaciones sobre la peronización de estudiantes, docentes e intelectuales de la UBA (DIP 2012, 2013, 2016, 2017a, 2017b, 2017c, 2017d, 2018, 2020).

${ }^{5}$ La izquierda peronista puede ser ubicada en el heterogéneo campo de la izquierda latinoamericana de los sesenta y setenta, ya que como sostiene Tortti $(2009,2014)$ formó parte del amplio conglomerado de fuerzas sociales y políticas de la nueva izquierda argentina, la cual protagonizó intensas protestas y levantamientos populares en esos años. Pese a que no fue un actor político homogéneo, adquirió cierta unidad de hecho que le permitió desplegar acciones y discursos que combinaban demandas sectoriales, la impugnación a la dictadura y la reivindicación de programas socialistas y antiimperialistas. Para Friedemann (2018), la izquierda peronista fue la expresión más significativa de la nueva izquierda argentina, mientras Caruso, Campos, vigo y Acha (2017) sostienen que es una categoría de análisis útil para caracterizar las tendencias anticapitalistas y socialistas del peronismo en los sesenta y setenta.

6 Para analizar estos debates, retomamos de Sarlo (2001, p. 91) el concepto de cuestión universitaria. El mismo hace referencia a las controversias sobre el perfil de la universidad y su relación con la sociedad, la cultura, la ciencia y los intelectuales. Estos temas tienen una faz académica y una ligada a posicionamientos políticos.
} 
El ocaso de la izquierda peronista en la Universidad de Buenos Aires: internas y debates ante la Ley Taiana 1973 - 1974

Nicolás Dip

Taiana. La normativa si bien fue aprobada el 14 de marzo de 1974, suscito una serie de controversias desde el año anterior. Es necesario tener en cuenta que entre 1973 y 1974 se designaron cinco rectores en la UBA: Rodolfo Puiggrós, Ernesto Villanueva, Vicente Solano Lima, Raúl Laguzzi y Alberto Ottalagano. Esa rápida sucesión de funcionarios de primera línea habla del grado de inestabilidad política que atravesó la institución, en un contexto nacional signado por fuertes conflictos internos en la fuerza política gobernante. En este breve lapso, los sectores universitarios de la izquierda peronista intervinieron en los debates y conflictos que terminaron en la sanción de la ley. El proceso tuvo un resultado paradójico, ya que por una parte la normativa incorporó parte de sus demandas sobre cómo organizar la universidad e incluso aceptó la propuesta de la Unión Cívica Radical (UCR) para que los rectores fueran elegidos por la misma comunidad académica. Pero, a la vez, otorgó herramientas legales que permitieron combatir al activismo político universitario y creó un terreno fértil para el fortalecimiento de los sectores más reaccionarios y represivos. En este marco, el estudio espera demostrar que la sanción de la Ley Taiana puede entenderse como el ocaso de la izquierda peronista en la UBA. ${ }^{7}$

\section{La asunción de Puiggrós y los primeros debates sobre la ley}

Puiggrós inició su gestión con una condición planteada de antemano en su mismo nombramiento por el presidente electo Héctor Cámpora el 29 de mayo de 1973.8 Debía ser el interventor de la rebautizada "Universidad Nacional y Popular de Buenos Aires" (UNPBA) hasta la sanción de una nueva ley universitaria que regularizara su funcionamiento, luego de la compleja situación atravesada por el país en los 18 años de proscripción del peronismo. ${ }^{9}$ En consecuencia, tenía

\footnotetext{
7 El escrito está acotado a la UBA, sin embargo no parte de la suposición de que dicha casa de estudio exprese la totalidad de problemas y debates en torno a la Ley Taiana. Pueden encontrarse otras universidades del país donde hay casos interesantes al respecto.

${ }^{8}$ Puiggrós fue uno de los primeros intelectuales del PC argentino en acercarse a Perón, en los años de sus primeros gobiernos (1946-1955). Tras el derrocamiento del peronismo tuvo un paso por México, donde se desempeñó como periodista y profesor de la UNAM, hasta volver en 1966 a la Argentina. Luego se exilió en México nuevamente en la década del setenta, tras la muerte de Perón en 1974 (ACHA, 2006; PUIGRRÓS, 2010).

9 No existió una normativa por el cambio de nominación, sino que fue impuesta por los protagonistas al momento de asumir las nuevas autoridades. La misma se reflejó luego en las resoluciones, publicaciones, solicitadas y documentos que empezó a emitir la UBA con posterioridad a la designación de Puiggrós.
} 
El ocaso de la izquierda peronista en la Universidad de Buenos Aires: internas y debates ante la Ley Taiana 1973 - 1974

dos objetivos inmediatos en su tarea en el rectorado: dar los primeros pasos en la "reconstrucción" de la casa de estudio y generar las condiciones para que sea debatida la normativa. ${ }^{10}$ Para impulsar ambas cuestiones, si bien tuvieron un rol destacado sus colaboradores más cercanos, quien jugó un papel clave fue la JUP, dirigida por José Pablo Ventura, en tanto se constituyó en el principal respaldo de Puiggrós junto a una parte de la militancia estudiantil no peronista.

La importancia de la organización que encabezó Ventura se manifestó inmediatamente. A tan sólo unos días de asumir, Puiggrós anunció una serie de medidas que desataron resistencias y oposiciones a su gestión. La primera fue la amnistía para todos los estudiantes que habían sido sancionados por razones políticas o gremiales en años anteriores (UBA, 1973a). La misma estaba en consonancia con la liberación y el indulto a los presos políticos que siguió a la asunción de Cámpora, aunque en el caso de la universidad adquiría un efecto simbólico especial al reconocer y resaltar la militancia estudiantil. La segunda disposición del interventor anulaba las renuncias y cesantías docentes producidas entre 1955 y 1973 (UBA, 1973b). El período considerado buscaba congregar el apoyo de un amplio abanico de universitarios, dado que la medida incluía a sectores que habían sido apartados de la UBA tras el derrocamiento del primer peronismo, como a los que sufrieron ese mismo destino en 1966. Un caso del primer grupo fue el del historiador nacionalista José María Rosa, mientras el reconocido físico Rolando García del segundo. ${ }^{11}$ De todas maneras, la intervención universitaria de 1973 también estuvo acompañada de nuevas renuncias, cesantías y expulsiones. La gestión de la UNPBA justificaba las exoneraciones haciendo alusión a que los profesores apartados habían respaldado al gobierno militar o pertenecían a grandes empresas privadas o multinacionales. ${ }^{12}$

\footnotetext{
10 Los dos objetivos inmediatos del rector-interventor estaban fundamentados en el decreto 35 que rubricó Cámpora el 29 de mayo de 1973. La normativa del ejecutivo fundamentaba la decisión en la necesidad de superar la "crisis" que atravesaban las casas de estudio. De esta manera, establecía un "régimen transitorio de gobierno" hasta que pudiera establecerse un nuevo ordenamiento legal que definiera los objetivos y sentara las bases de la "reconstrucción universitaria" (ARGENTINA, 1973a).

11 Varios docentes y no docentes cesanteados y renunciantes entre 1955 y 1973 fueron reincorporados (LA REINCORPORACIÓN..., 1973). Además pueden consultarse distintas resoluciones del rectorado (UBA, 1973b; 1973g; 1973h).

${ }^{12}$ En el mes de julio, el rectorado directamente dispuso la incompatibilidad de tareas docentes con el desempeño de funciones jerárquicas o de asesoramiento en empresas extranjeras o multinacionales (UBA, 1973e).
} 
El ocaso de la izquierda peronista en la Universidad de Buenos Aires: internas y debates ante la Ley Taiana 1973 - 1974

Nicolás Dip

Inmediatamente a esas dos resoluciones que sancionó Puiggrós el 8 de junio, se desató una protesta de un grupo de docentes que reivindicaba al ex rector Bernabé Quartino y al ex decano de Ciencias Exactas Raúl Zardini. ${ }^{13}$ Este sector acusaba al nuevo interventor de permitir la "infiltración de marxistas y trotskistas" dentro de la casa de estudio porteña (PRIMER..., 1973a). Sus denuncias tuvieron eco en La Nación y La Prensa, dos diarios de tirada nacional que dedicaron una serie de notas críticas a la situación universitaria abierta tras la asunción de Cámpora. ${ }^{14}$ El principal foco opositor se desarrolló en Exactas y, sobre todo, en la Facultad de Derecho. La designación de Mario Kestelboim como delegado interventor produjo la renuncia de docentes que habían ocupado importantes cargos políticos y judiciales tras el derrocamiento del primer peronismo. Entre los que dimitieron estaban Roberto Alemann, el ex ministro de Economía de Arturo Frondizi, y juristas como Marco Aurelio Risolía, Luis Carlos Cabral, Jaime Smart y Gabino Salas. Los dos primeros habían sido integrantes de la Corte Suprema de Justicia durante la dictadura saliente, mientras los segundos habían formado parte de la Cámara Federal en lo Penal en ese mismo período. Esta última era recordada como la "Cámara del Terror" o "El Camarón” por haber sido un fuero especial encargado de enjuiciar la actividad "subversiva" de las organizaciones político-militares..$^{15}$ La distancia de estos sectores con Kestelboim y su equipo no podía ser más amplia. El decano y la mayoría de quienes lo acompañaban provenían de la Asociación Gremial de Abogados y de la Agrupación de Abogados Peronistas, dos entidades que nucleaban a defensores

\footnotetext{
13 Quartino fue un geólogo que se desempeñó como interventor en la Facultad de Ciencias Exactas entre 1966 y 1967. Con la asunción de Lanusse, ocupó el rectorado de 1971 a 1973 . Un tiempo antes de la llegada de Cámpora al gobierno, fue reemplazado por Carlos Durrieu. Zardini, por su parte, fue geólogo e interventor en Ciencias Exactas entre 1969 y 1973.

${ }^{14}$ Frente a los cuestionamientos de los diarios tradicionales, la revista Militancia Peronista para la Liberación dedicó numerosas notas a favor de la gestión de Puiggrós, a la vez que denunciaba a La Nación y La Prensa por intentar crear una imagen de "caos" sobre la universidad. Esta publicación fue dirigida por Rodolfo Ortega Peña y Eduardo Duhalde entre mediados de 1973 y 1974. Tuvo un total de 38 números hasta que fue clausurada en junio de 1974. A partir de ese momento, la revista cambió de nombre y pasó a llamarse De Frente (MILITANCIA PERONISTA PARA LA LIBERACIÓN, 1973a).

15 Junto al lanzamiento del GAN, el régimen de Lanusse había reforzado mecanismos represivos ilegales e instrumentado nuevas disposiciones para lograr mayor efectividad en la represión legal. Dos ejemplos de esta cuestión fueron: por un lado, la sanción de la ley 19.081, la cual autorizaba la intervención de las Fuerzas Armadas para "combatir la subversión"; por otro lado, la ley 19.110, que reglamentaba el funcionamiento de la Cámara Federal en lo Penal para el juzgamiento de la actividad "subversiva".
} 
El ocaso de la izquierda peronista en la Universidad de Buenos Aires: internas y debates ante la Ley Taiana 1973 - 1974

Nicolás Dip

de presos políticos fuertemente politizados. Es necesario aclarar que las dimisiones no sólo se habían producido como rechazo a la llegada de Kestelboim, sino también porque la JUP había irrumpido en las aulas exigiendo la renuncia de numerosos docentes a principios de junio (PEREL; RAÍCES; PEREL 2007; CHAMA; GONZÁLEZ CANOSA, 2011; DIP, 2018).

Frente a las primeras manifestaciones de oposición a Puiggrós y los pedidos de desplazamiento del decano de Derecho, la organización de Ventura impulsó el 11 de junio una asamblea en esa casa de estudio y una movilización ante el Ministerio de Educación (LA GESTIÓN..., 1973). A esto se sumó que al día siguiente, el interventor de la UNPBA brindó una conferencia de prensa durante la cual afirmó que existían "maniobras" orientadas a desacreditar a sus funcionarios y a mostrar una imagen de "caos" en la universidad. A la vez defendió a Kestelboim frente a lo que consideraba un "grupito minúsculo desplazado" que creaba dificultades y volvió a destacar el activismo estudiantil. Además, anunció la restitución del título doctor honoris causa que le habían anulado a Perón en 1955 y comunicó que estaba trabajando con todas las facultades en un nuevo sistema de ingreso sin ningún tipo de limitaciones, cupos ni aranceles. ${ }^{16}$ Este último punto no sólo debe ser entendido como expresión de una política de gratuidad y libre acceso a la universidad, sino también como un reconocimiento al movimiento estudiantil, dado que una de sus principales demandas en los años dictatoriales había sido justamente el ingreso irrestricto. ${ }^{17}$

En esa misma conferencia de prensa del 12 de junio, Puiggrós informó la creación de una comisión destinada a generar aportes para la redacción de la ley universitaria que el gobierno impulsaría en el corto plazo. Como indicamos previamente, el nuevo interventor de la UNPBA debía encauzar los primeros

\footnotetext{
16 "Apoyo de estudiantes y docentes jóvenes ratifica su línea de gobierno", en La Opinión, 13 de junio 1973. La restitución del título doctor honoris causa a Perón se tramitó en la UBA el 14 de junio de 1973 (UBA, 1973c). También se impulsaron otras medidas similares como la designación de profesores eméritos, entre los cuales estaban José María Rosa, Hernán Benítez, Leonardo Castellani, Juan José Hernández Arregui, entre otros (UBA, 1973f).

${ }^{17}$ En agosto de 1973 se terminó creando, para implementar al año siguiente, un curso introductorio único, no limitativo, válido para todas las facultades, con un requisito de asistencia al 75 por ciento de las clases. Se diferenciaba de los realizados en años anteriores, los cuales culminaban con un examen y una selección por orden de mérito, según la cantidad de vacantes. Sin embargo, esta propuesta finalmente fue suspendida y el ingreso irrestricto se encauzó directamente en cada facultad. Para un análisis de las políticas que intentó instrumentar Puiggrós en su corta gestión, puede consultarse Friedemann (2015).
} 
El ocaso de la izquierda peronista en la Universidad de Buenos Aires: internas y debates ante la Ley Taiana 1973 - 1974

pasos de la institución, pero también generar debates y propuestas en relación a la futura normativa. Con ese objetivo, el 15 de junio constituyó una comisión integrada por Kestelboim, Miguel Virasoro, Mario Testa y Justino O’Farrell, los decanos de Derecho, Ciencias Exactas, Medicina y de Filosofía y Letras, respectivamente. La misma estaba bajo la coordinación de la Secretaría de Planeamiento del rectorado, a cargo del ex Cátedras Nacionales (CN) Jorge Carpio. ${ }^{18} \mathrm{~A}$ instancias de la comisión y de esta área de la UNPBA se propusieron dos iniciativas. Una fue el lanzamiento de una serie de publicaciones titulada Aportes para la Nueva Universidad, con la intensión de recopilar materiales y propuestas. En su edición no sólo tuvieron en cuenta experiencias históricas como la Universidad Obrera Nacional, discursos de Perón y Cámpora, sino también proyectos de ley universitaria de la UCR, la Alianza Popular Revolucionaria y de otras casas de estudio nacionales e incluso privadas, como la Universidad Católica y del Salvador. ${ }^{19}$ La difusión de documentos de otras fuerzas políticas era acorde al discurso sostenido por Puiggrós respecto a la legitimidad del activismo estudiantil y a su amplia convocatoria de peronistas y reformistas. ${ }^{20}$

La otra iniciativa de la comisión de decanos que funcionó bajo la dirección de la Secretaría de Planeamiento, fue la elaboración de un documento de discusión titulado "Lineamientos generales para la elaboración de la ley universitaria". El escrito recuperaba los tres ejes centrales del proyecto de universidad de la JUP y ADUP publicados en la revista Envido poco tiempo atrás (ADUP, 1973; JUP, 1973a). Un primer eje buscaba articular el papel orientador del Estado en la educación superior con la participación de los estamentos universitarios y de la comunidad. Para esto, el documento de la comisión de decanos consideraba que el gobierno de la universidad debía estar compuesto

\footnotetext{
18 La comisión fue creada por resolución del Consejo Superior el 15 de junio 1973 (UBA, 1973d; PUIGGRÓS..., 1973). También véase Entrevista a Jorge Carpio, C.A.B.A., 30/10/2015 y 20/11/2015

${ }^{19}$ Aportes para la Nueva Universidad, Secretaría de Planeamiento, UNPBA, № 1, julio 1973; № 2, julio 1973; № 3, agosto 1973; № 4, septiembre 1973; № 5, enero 1974; № 6-7, mayo-junio 1974.

${ }^{20}$ En su primer discurso como interventor, Puiggrós solicitó el apoyo no sólo de peronistas, sino de todos los que compartían la idea de liberación nacional y pretendían seguir el "camino socialista" que el "país había elegido". La misma dirección de la Federación Universitaria de Buenos Aires (FUBA) fue recibida por Puiggrós al otro día de su asunción (LA INTERVENCIÓN..., 1973d).
} 
por: a)- un rector elegido por el poder ejecutivo; b)- representantes de docentes, estudiantes y no docentes, seleccionados por el voto obligatorio y directo de sus respectivos claustros, en elecciones donde pudieran participar listas propiciadas por fuerzas políticas; y c)- un "cuarto estamento" conformado por referentes vinculados a asociaciones vecinales, gremiales u otras formas de organización comunitarias. El segundo eje proponía que la formación universitaria conjugara trabajo, investigación y enseñanza. En este punto, era central superar la actividad exclusivamente intelectual mediante la participación de estudiantes y docentes en ámbitos productivos, administrativos o culturales. A esto se sumaba la incompatibilidad entre el ejercicio de la docencia y el desempeño de funciones en empresas extranjeras o multinacionales. El último eje establecía la necesidad de garantizar al conjunto de la población el acceso gratuito e irrestricto a la educación superior. El Estado debía asegurar todos los medios para ese fin y la universidad generar cursos de orientación vocacional para priorizar la inscripción en profesiones acordes a las necesidades del país. ${ }^{21}$

Los "Lineamientos generales para la elaboración de la ley universitaria", redactados por la comisión de decanos que seleccionó Puiggrós, fueron presentados como un primer borrador para que se discutiera entre docentes y estudiantes de distintas facultades. En este punto, la JUP volvió a tener un papel clave porque, desde su propia constitución en el mes de abril, impulsó las "Mesas Universitarias para la Reconstrucción Nacional" (MAÑANA..., 1973; JUP, 1973b). Mediante esa consigna la agrupación liderada por Ventura realizó una serie de actividades a las cuales invitaba a docentes y funcionarios a discutir la política universitaria general y los planes de estudio de las carreras. Las fuertes críticas que recibió la UNPBA en medios como La Nación y La Prensa, en gran parte eran producto de esa estrecha cercanía entre las autoridades de las facultades y la militancia estudiantil. La notable identificación política entre los dos polos de la vida universitaria fue una característica distintiva de toda esta experiencia. A ello se sumó el impulso iconoclasta desplegado en muchas casas de estudio, donde asumieron primeros puestos de gestión jóvenes docentes que no contaban con

\footnotetext{
${ }^{21}$ Los "Lineamientos generales para la elaboración de la ley universitaria" fueron publicado en agosto de 1973 en el tercer número de Aportes para la Nueva Universidad.
} 
El ocaso de la izquierda peronista en la Universidad de Buenos Aires: internas y debates ante la Ley Taiana 1973 - 1974

Nicolás Dip

una extensa trayectoria político-académica. ${ }^{22}$ De esta manera, el rectorado de Puiggrós dio sus primeros pasos en medio de conflictos y promesas de cambio, con un estudiantado peronista que se sentía parte y garante de la intervención.

\section{La interna peronista en la UNPBA}

A los primeros altercados desatados en junio por las disputas entre los universitarios opositores y afines a Puiggrós, se sumó otro factor conflictivo que con el tiempo empezaría a tener cada vez más repercusiones en la UNPBA: la interna del movimiento peronista. Tras la "masacre de Ezeiza”, el avance de los sectores sindicales y de derecha precipitó la renuncia de Cámpora el 13 de julio de 1973. ${ }^{23}$ La asunción de Raúl Lastiri, presidente de la Cámara de Diputados y yerno del ministro de Bienestar Social López Rega, como primer mandatario provisional puso en alerta a toda la izquierda peronista y generó una sensación de incertidumbre respecto a sus áreas de influencia en las reparticiones estatales. ${ }^{24}$ En el caso de la universidad porteña, la JUP incluso tomó facultades un día antes de la dimisión de Cámpora, denunciado "un golpe orquestado por la CIA" desde el Ministerio de Bienestar Social con apoyo de la "burocracia sindical" (PUIGGRÓS..., 1973). El nuevo panorama político generó un interrogante alrededor de la continuidad de Puiggrós. Frente a estos acontecimientos, la JUP convocó a

\footnotetext{
22 Una nota de La Opinión hace una comparación estereotipada entre los perfiles de los interventores de la gestión Puiggrós y de los sectores docentes que cuestionaban y pedían su desplazamiento. Los primeros se caracterizaban por: a)- Jóvenes, militantes políticos y opositores a la última dictadura militar; b)- Receptores del aval político de la mayoría del alumnado peronista y no peronista; c)- Reivindicación de un programa de liberación y posturas radicalizadas. En cambio, los principales rasgos de los segundos eran: a)- Titulares de extensa carrera universitaria comprometidos con la dictadura saliente; b)- Respaldo político de sectores extrauniversitarios enfrentados al gobierno de Cámpora; c)- Opositores a la intervención de Puiggrós a la que consideraban "izquierdista” (DISPUTAS..., 1973h).

23 Acordamos con Marina Franco (2012, p.50) que el conflicto interno del peronismo ya era perceptible desde la asunción de Cámpora, pero con el episodio de Ezeiza pasó a ocupar el espacio público y nacional. A esto hay que agregar que la Tendencia sufrió desplazamientos antes de los hechos de Ezeiza, como la destitución de Rodolfo Galimberti en el cargo de representante de la JP en el Consejo Superior del MNJ. Jorge Bernetti, un protagonista de la época, llegó a caracterizar a ese suceso como "el inicio de la derrota dentro de la victoria", debido que a los pocos días del triunfo electoral empezaron a manifestarse los primeros trazos de una etapa de lucha interna (BERNETTI, 2011, p. 81).

${ }^{24}$ Lastiri estaba casado con la hija de López Rega y había llegado a la presidencia de la Cámara de Diputados a instancias de él. Cuando Cámpora y Solano Lima renunciaron, debía asumir interinamente el vicepresidente de la Cámara de Senadores, Alejandro Díaz Bialet. Sin embargo, lo enviaron al exterior en una misión diplomática y debió pedir licencia. En la línea sucesoria le seguía el mismo Lastiri (DE RIZ, 1981, p. 92).
} 
El ocaso de la izquierda peronista en la Universidad de Buenos Aires: internas y debates ante la Ley Taiana 1973 - 1974

Nicolás Dip

un acto en la Facultad de Ciencias Económicas en respaldo al interventor y a la candidatura de Perón como presidente. El hecho puso de manifiesto el amplio arco de adhesiones que había conseguido la gestión de la UNPBA, dado que aquella noche del 17 de julio también movilizaron otras fuerzas políticas, como el Movimiento de Orientación Reformista (MOR), el Frente de Agrupaciones Universitarias de Izquierda (FAUDI) y Franja Morada (FM) ${ }^{25}$. Durante la concentración, Ventura declaró que existían sectores dentro del movimiento peronista que pretendían "quebrar su carácter revolucionario” y exigía al gobierno provisional de Lastiri "no innovar" en la política iniciada por Cámpora y acompañada por Puiggrós. Al día siguiente, seguía sin confirmarse la continuidad del interventor en su cargo, hasta que él mismo declaró públicamente que Taiana le "ratificó su confianza" (EL RESPALDO..., 1973; MILITANCIA PERONISTA PARA LA LIBERACIÓN, 1973b).

Luego de estos sucesos, se organizó el 7 de septiembre el Primer Congreso Nacional de la Juventud Universitaria Peronista en la Facultad de Derecho. Durante el encuentro, realizado el "Día del Montonero", fue conformada la "Mesa de Mando de la Conducción Nacional" de la JUP, la cual pasó a estar integrada por el referente porteño Ventura y los líderes del resto de la regionales del país. ${ }^{26}$ Al mitin concurrieron desde militantes del Movimiento de Sacerdotes para el Tercer Mundo hasta delegados de la Juventud Radical y la Federación Juvenil Comunista. En el cierre, Ventura declaró que la militancia había roto "el aparato" que los "enemigos" intentaban poner entre Perón y su pueblo. Por esta razón, consideraba que su candidatura en las inminentes elecciones presidenciales era un "acontecimiento histórico trascendente" en el camino hacia el socialismo nacional (PRIMER, 1973b).

\footnotetext{
${ }^{25}$ El MOR era la agrupación estudiantil que respondía al Partido Comunista (PC), mientras el FAUDI era el brazo estudiantil del Partido Comunista Revolucionario (PCR) y FM del radicalismo.

${ }^{26}$ El "Día del Montonero" es rememorado los 7 de septiembre por los asesinatos de Fernando Abal Medina y Carlos Gustavo Ramus en 1970, dos de los fundadores de la organización. El resto de la "Mesa de Mando de la Conducción Nacional" de la JUP estaba integrada por Ramón Puch (Regional II); Alfredo Martelloto (Regional III), Juan Carlos Benítez (Regional IV), Ramón Ponce (Regional V); Carlos Sanhueza (Regional VI) y Jorge Aluano (Regional VIL). La JUP tenía la misma organización en regionales que el resto de los grupos de superficie que respondían a Montoneros. Cada regional aludía a la siguiente división territorial: I Buenos Aires, II Litoral, III Córdoba, IV Noroeste, V Noreste, VI Cuyo, VII Sur (PERDÍA, 2013, p.183).
} 
A pesar de las declaraciones entusiastas de la JUP, el abrumador triunfo electoral de Perón en los comicios del 23 de septiembre y el asesinato de José Ignacio Rucci tan sólo dos días después, volvió a recrudecer la interna peronista. Ésta tuvo sus propias manifestaciones en el interior de la UNPBA. En la jornada siguiente al atentando contra el secretario general de la CGT, El Descamisado, el órgano de prensa oficial de la JP Regionales y Montoneros, anunció que se cernía una "inminente amenaza" contra la universidad (LA CONSIGNA..., 1973). El 28 de ese mismo mes, Ventura, Ernesto López y Cristián Caretti brindaron en la Facultad de Farmacia y Bioquímica una conferencia de prensa en representación de la JUP, la ADUP y la Unión de Estudiantes Secundarios (UES), respectivamente. En ella leyeron un documento donde se consideraba que el asesinato de Rucci agudizaba la "ofensiva de sectores reaccionarios e infiltrados en el movimiento" y que éstos buscaban impedir la "reconstrucción universitaria". A su entender, eso había quedado de manifiesto con la irrupción en las casas de estudio de grupos armados como la Concentración Nacional Universitaria (CNU) y la Alianza Libertadora Nacionalista, pero sobre todo con el asesinato de Enrique Grynberg, un militante de la JP Regionales que era director del Centro de Investigaciones Aplicadas de la UNPBA. ${ }^{27}$

La tan anunciada ofensiva finalmente llegó el 1 de octubre cuando el ministro Taiana le solicitó la renuncia a Puiggrós por pedido del propio Perón. Al día siguiente, el interventor la presentó y Lastiri, todavía en ejercicio como presidente provisional, dictó el decreto 1.574 para designar interinamente en su puesto al decano de odontología Alberto Banfi (ARGENTINA, 1973b). Ese mismo día, a su vez, fue publicado en La Opinión el "Documento Reservado" del Consejo Superior del Movimiento Nacional Justicialista (MNJ). Este escrito intrapartidario consideraba que el asesinato de Rucci había sido un punto de inflexión y en consecuencia llamaba a librar una "guerra" contra los "grupos subversivos infiltrados" en el peronismo. Para eso, juzgaba necesario acatar sin vacilaciones las directivas de Perón, utilizar todos los medios disponibles e incluso los resortes

\footnotetext{
27 Grynberg fue asesinado al día siguiente del atentado contra Rucci. Mientras los demás frentes de masas de la JP Regionales daban declaraciones públicas similares a la JUP, los militantes se iban enterando sorpresivamente que los propios Montoneros habían asesinado al dirigente de la CGT (LA JUP..., 1973).
} 
El ocaso de la izquierda peronista en la Universidad de Buenos Aires: internas y debates ante la Ley Taiana 1973 - 1974

Nicolás Dip

del Estado para "reprimir con vigor". Para el diario de Jacobo Timerman, dicho documento había sido anunciado por el mismo Perón en una reunión con gobernadores convocada por Lastiri. Además, según La Opinión, el pedido de renuncia a Puiggrós constituía "el punto más alto" del proceso de depuración ideológica del justicialismo (DRÁSTICAS..., 1973).

Frente a estas noticias y la dimisión del interventor de la UNPBA, no se quedaron impasibles ni el activismo universitario ni el propio Puiggrós y sus funcionarios. Desde el momento en que se conoció el pedido de Taiana el 1 de octubre, todos los decanos interventores hicieron una conferencia de prensa y dirigieron una carta a Perón donde se presentaban como "soldados disciplinados del movimiento" y solicitaban que confirme a Puiggrós en su cargo (A PUIGGRÓS..., 1973). Con la misma demanda, ese día a la noche la JUP convocó a una concentración en la Facultad de Ciencias Económicas y a una movilización al Ministerio de Educación. Estas manifestaciones fueron masivas y contaron con la participación de las dos FUA, la FUBA e incluso de sectores estudiantiles críticos de la intervención como TUPAC y TERS. ${ }^{28}$ Al día siguiente, la JUP ocupó todas las facultades y el rectorado con el resto de la militancia y el apoyo de los decanos (LA JUVENTUD..., 1973b; OCUPARON..., 1973).

Ante esta situación, Puiggrós terminó reuniéndose con Perón y Solano Lima el 3 de octubre. Llamativamente, en ese encuentro el líder del peronismo le negó que haya sido él quien pidió su renuncia. Luego de la reunión, la JUP y Puiggrós realizaron una serie de declaraciones públicas donde informaron lo acontecido y volvieron a acusar al "lastirismo" y al "lopezreguismo" de intentar frenar la edificación de la UNPBA (PERÓN..., 1973; TRIUNFÓ..., 1973). A esto se sumó que el 4 de octubre la JUP encabezó nuevamente una nutrida marcha al rectorado donde finalmente lograron que Banfi diera un "paso al costado" (EL PROBLEMA..., 1973). Sin embargo, al día siguiente Puiggrós no volvió a ocupar su cargo, sino que

\footnotetext{
${ }^{28}$ Debe recordarse que la Federación Universitaria Argentina (FUA) estaba dividida en dos sectores desde noviembre de 1970. La FUA La Plata estaba en manos del MOR; mientras la FUA Córdoba era conducida por radicales de FM y socialistas del Movimiento Nacional Reformista (MNR). En esta última también participaban vertientes de izquierda como el FAUDI, la Tendencia Estudiantil Revolucionaria Socialista (TERS) y la Tendencia Universitaria Popular Antiimperialista y Combativa (TUPAC). TERS era el grupo universitario del colectivo trotskista Política Obrera; mientras TUPAC estaba vinculada a Vanguardia Comunista (SE ACEPTA..., 1973).
} 
El ocaso de la izquierda peronista en la Universidad de Buenos Aires: internas y debates ante la Ley Taiana 1973 - 1974

Nicolás Dip

Taiana nombró ad-referéndum del poder ejecutivo al secretario general Ernesto Villanueva como encargado provisorio del rectorado, hasta que Perón fuera investido como presidente el 12 de octubre (HAY..., 1973d).

Frente a la designación de un hombre de su propio espacio político, la JUP concluyó las ocupaciones y las medidas de fuerza (TRIUNFÓ..., 1973). Al asumir, Villanueva (1973, apud RECALDE, 2012) declaró que iba a continuar con la política de Puiggrós y anunció su designación como Profesor Emérito de la Facultad de Filosofía y Letras. ${ }^{29}$ Una vez que Perón fue proclamado primer mandatario de la Nación, el ex CN y militante de Montoneros continuó a cargo del rectorado pese a no ser ratificado. El 25 de octubre, Taiana propuso en su reemplazo a Rodolfo Agoglia, en ese momento rector interventor de la UNLP, pero recibió otra vez la negativa de la JUP. ${ }^{30}$ Luego de este compás de espera, a fines de noviembre un decreto del poder ejecutivo confirmó en el cargo a Villanueva (HABLA..., 1973a; DESIGNÓSE..., 1973). Con tan sólo 28 años, se convirtió en la primera autoridad más joven en toda la historia de la universidad porteña.

¿Cómo se interpretó entonces la renuncia de Puiggrós y su reemplazo por Villanueva? Los sectores estudiantiles y docentes vinculados a la JUP, ADUP, la JP Regionales y Montoneros lo mostraron como un triunfo en las páginas de El Descamisado, haciendo un esfuerzo por explicar que Perón estaba de su parte y que tanto el mismo líder como Taiana e incluso Banfi habían sido involucrados en una "maniobra" de López Rega. ${ }^{31}$ Otros espacios donde también se expresaban voces a favor de la UNPBA, eligieron mostrar un diagnóstico menos triunfalista. Este fue el caso de Ciencia Nueva, una revista que publicaba con regularidad trabajos de docentes y profesionales vinculados al Consejo Tecnológico de Rolando García; algunos de los cuales ocupaban cargos universitarios, como Enrique Martínez en el decanato de Ingeniería e Iván Chambouleyrón en el

\footnotetext{
${ }^{29}$ El nombramiento se produce el 9 de octubre de 1973 (UBA, 1973i). La conferencia de prensa de Villanueva está reproducida en Recalde (2012, p. 315-322).

30 Se puede consultar (AGOGLIA..., 1973; NO REEMPLAZA...,1973; DISCUTE..., 1973; LA JUP..., 1973).

${ }^{31}$ La revista El Descamisado realizó una cronología de lo que caracterizó como una "exitosa semana de lucha" (TRIUNFÓ..., 1973). Sergio Bufano sostiene que este tipo de discursos de la JUP mostraban la difícil y enrevesada decisión de la JP Regionales y Montoneros de eludir el enfrentamiento con Perón y no involucrarlo en las medidas que adoptaba el gobierno, perjudicándolos directa o indirectamente (BUFANO; TEXIDÓ, 2015, p.163-164).
} 
El ocaso de la izquierda peronista en la Universidad de Buenos Aires: internas y debates ante la Ley Taiana 1973 - 1974

Nicolás Dip

rectorado de la Universidad Tecnológica Nacional ${ }^{32}$. En su número del 27 de octubre, Ciencia Nueva difundió una nota titulada "U.B.A." a modo de editorial, donde hacía una defensa de Puiggrós y se lamentaba por su renuncia. De todas maneras, alegaba que su dimisión iba a figurar entre los "hechos insólitos" en la "larga y azarosa" historia de la UBA, porque fue requerida en nombre del presidente electo (Perón) que formalmente no podía pedirla ni aceptarla; admitida por un ministro (Taiana) que decía actuar en cumplimiento de órdenes, pero cuando dichas órdenes fueron desmentidas mantuvo la decisión como algo irreversible; y objetada por un estudiantado de amplio espectro político que apoyaba vigorosamente a Puiggrós, pero que aceptó su relevo con una “moderación sin precedentes", ya que denunció "la maniobra” y la repudió, aunque se abstuvo de atacar sus "orígenes aparentes" (U.B.A..., 1973).

Este editorial de Ciencia Nueva mostraba la difícil situación de los integrantes de la izquierda peronista en la universidad, especialmente de la JUP, la principal fuerza de movilización que incluso tenía un poder de veto sobre las políticas que atenían a las casas de estudio. No pudo mantener a Puiggrós, pero logró conservar a un docente de su espacio político al frente del rectorado y paralizar no sólo la designación de Banfi, sino también la de Agoglia. A esto se sumaba otra cuestión producto de la politización particular de la JUP. La organización había surgido en el contexto del triunfo de Cámpora para atender las especificidades del estudiantado en el marco de dos referencias políticas: el gobierno peronista, al que pretendía aportarle políticas universitarias, y Montoneros, organización con la que seguiría el camino de la "guerra popular y prolongada" en busca del socialismo nacional ${ }^{33}$. Sus dos referentes ahora entraban en conflicto y eso ponía a la JUP en una difícil encrucijada a la hora de legitimar su política en la UNPBA.

\footnotetext{
32 Rolando García había sido decano de la Facultad de Ciencias Exactas y exiliado del país por la represión que sufrió en "La noche de los batones largos" de 1966. En 1973, se mostraba como un ferviente partidario del peronismo y presidía el Consejo Tecnológico del Movimiento Nacional Justicialista, el cual había ayudado a crear el 14 de julio de 1972 luego de su encuentro con Perón en Madrid. Este organismo de profesionales se había constituido con la idea de planificar políticas para el futuro gobierno. Su plataforma fundacional recalcaba la importancia de la "doctrina justicialista" y la necesidad de establecer el socialismo nacional en Argentina.

3 Para una cobertura del acto de lanzamiento de la JUP (MAÑANA..., 1973; CREA..., 1973; GALIMBERTI..., 1973; BASES..., 1973).
} 


\section{La izquierda peronista ante la Ley Taiana}

Desde el inicio del tercer gobierno peronista se había afirmado que la nueva legislación universitaria debía surgir del aporte y la discusión de diversos sectores, especialmente de la comunidad académica. El propio Cámpora (1973, p.187-188) había resaltado esto ante la asamblea legislativa el día de su asunción e incluso figuraba en los considerandos de su decreto de intervención de las universidades nacionales (ARGENTINA, 1973a). Sin embargo, el 11 de junio de 1973, el ministro Taiana anunció oficialmente la creación de una comisión especial presidida por él para confeccionar las bases de una nueva normativa. En ella no había ningún representante de la izquierda peronista y entre sus principales integrantes estaban Ricardo Guardo, Horacio Domingorena y Jorge Vanossi. El primero había sido el redactor de la primera ley universitaria del peronismo (13.031), el segundo de la normativa que habilitó a las universidades privadas a otorgar títulos académicos y el tercero el secretario académico de la UBA en la gestión de Carlos Durrieu, el último rector de la dictadura saliente. ${ }^{34}$

Frente a los primeros rumores de que Taiana pretendía contrarrestar el peso de los actores vinculados a la Tendencia y cerrar la discusión (FUA..., 1973; DESFAVORABLE..., 1973), el mismo ministro brindó una conferencia el 25 de junio ante los interventores de las universidades nacionales y les pidió que elevaran propuestas concretas para ser tenidas en cuenta en la elaboración de la ley. Indicó como fecha límite el 31 de agosto porque pretendía presentar el proyecto al congreso ese mismo año (JORGE..., 1973). Por su parte, Puiggrós ya había creado el 15 de junio una comisión de decanos con ese fin, bajo la coordinación de la Secretaría de Planeamiento a cargo de Carpio, un sociólogo ex CN referenciado con la JP Regionales. Desde este espacio, se impulsó la publicación Aportes para la Nueva Universidad y se elaboró el documento "Lineamientos generales para la elaboración de la ley universitaria". El mismo fue presentado por Testa, el decano de Medicina, en una conferencia de prensa a principios de agosto y entregado a la comisión del Ministerio de Educación que presidía Taiana

\footnotetext{
${ }^{34}$ La comisión comenzó a funcionar el 15 de junio. Los restantes miembros eran José Cravero, Julio Fortezza y su secretario Alberto Godoy (CREAN..., 1973; LA GESTIÓN..., 1973, HOY..., 1973).
} 
El ocaso de la izquierda peronista en la Universidad de Buenos Aires: internas y debates ante la Ley Taiana 1973 - 1974

Nicolás Dip

(LA ELABORACIÓN..., 1973). ${ }^{35}$ Como señalamos anteriormente, estos lineamientos para discutir la nueva normativa que elaboraron los funcionarios de Puiggrós estaban en sintonía con los primeros proyectos sobre universidad que habían difundido la JUP y ADUP en la revista Envido antes de la asunción de Cámpora.

Hacia fines de 1973, Puiggrós ya no estaba más al frente de la UNPBA y Taiana aún no había elevado ninguna propuesta al parlamento. Sin embargo, paralelamente al congreso del 22 de diciembre donde surgió la Federación Universitaria para la Liberación Nacional de Buenos Aires (FULNBA), empezó a correr la noticia de que Perón y Balbín se habían puesto de acuerdo para sancionar una ley universitaria en las sesiones extraordinarias de verano ${ }^{36}$. A fin de mes, Talento en conferencia de prensa leyó un documento en el cual las distintas fuerzas de la federación porteña llamaban a posponer el tratamiento para después de febrero, debido a que en esa fecha era muy difícil la participación de los universitarios (LA FULNBA..., 1973). La preocupación central del presidente de la FULNBA era que durante el receso vacacional decaía la militancia estudiantil y eso les quitaba capacidad de intervenir. Finalmente, Perón y Taiana firmaron el proyecto de ley y lo presentaron al senado el 12 de febrero de 1974. Mientras FM, el FAUDI y TUPAC realizaron una movilización al congreso en protesta el día 20; la JUP decidió organizar un encuentro el 22 en la Facultad de Derecho para fijar su posición ante la nueva situación (LA LEY..., 1974, LEY..., 1974; CRONISTA COMERCIAL, 1974; MANIFESTACIÓN..., 1974).

En el acto realizado por la noche en el aula magna de la casa de estudio que encabezaba Kestelboim, Ventura leyó una declaración política en la cual anunciaba el apoyo de la JUP al proyecto de ley del poder ejecutivo, a la vez que solicitaba modificaciones y la continuidad de los actuales interventores una vez sancionado el texto legal e iniciado el período de normalización. El respaldo de la JUP lo justificaba porque la propuesta enviada al congreso reconocía principios

\footnotetext{
35 Como vemos, el pedido de Taiana se cumplió en la UNPBA durante el tiempo acordado. Además, ese mismo mes se publicó el documento de la comisión de decanos en la revista institucional de la universidad, titulado "Lineamientos generales para la elaboración de la ley universitaria" (LINEAMIENTOS..., 1973).

${ }^{36}$ El 22 de diciembre en el aula magna de la Facultad de Medicina fue constituida la FULNBA como un acto simbólico de transformación de la FUBA ante los nuevos tiempos. Su presidencia quedó a cargo de Miguel Talento de la JUP y la secretaría general en manos de Rafael Pascual de FM, ambos estudiantes de Derecho.
} 
que la agrupación había sostenido desde sus inicios (LA UNIVERSIDAD..., 1974; POSICIÓN..., 1974). Entre ellos, Ventura resaltaba la definición de las universidades como "comunidades de trabajo", encargadas de formar profesionales e impartir la enseñanza técnico-científica para aportar a la "liberación nacional" y solucionar los problemas regionales del país; además de orientarlas a la promoción de cultura nacional como a la producción de bienes y servicios sociales, con el fin de eliminar la distinción entre trabajo manual e intelectual (Art. 10 y 20). ${ }^{37}$ También destacaba que explicite que la universidad no podía aceptar subsidios o préstamos de organismos internacionales, junto a la prohibición de ejercer cargos docentes o administrativos en paralelo con funciones en empresas multinacionales (Art. 110 y 47으). Por otro lado, Ventura consideraba importante que el proyecto contemplara el establecimiento de la gratuidad de la enseñanza universitaria y dos elementos que caracterizaba como de "suma corrección y legitimidad": la presencia del poder ejecutivo en el gobierno de las casas de estudio, a través de su potestad de designar a los rectores, y la participación de los claustros docentes, estudiantiles y no docentes (Art. 23ํy y 33ㅇ); además de garantizar vías para la colaboración de la comunidad extra universitaria (Art. 27ํㅡ).

Efectivamente, estos ejes del proyecto de Taiana compartían los grandes lineamientos de las propuestas iniciales de la JUP, ADUP y del documento de la comisión de decanos que había creado Puiggrós en la Secretaría de Planeamiento de la UNPBA. No obstante, la inminente sanción de la ley y el contexto político hizo precisar a la JUP algunas de sus ideas en relación con estos temas (LA UNIVERSIDAD..., 1974; POSICIÓN..., 1974). Así lo manifestó el mismo Ventura en su lectura de las modificaciones que solicitaban para la normativa. La primera se refería a que en los órganos de gobierno, los claustros de docentes, estudiantes y no docentes tuvieran la misma cantidad de representantes, no una distribución del 60, 30 y 10 por ciento como establecía el proyecto del ejecutivo (Art. 30). La segunda pretendía eliminar la cláusula que avalaba la remoción de docentes por “proselitismo partidario” o “ideas contrarias al sistema democrático” (Art. 12으), debido a que este tipo de disposiciones podrían dar lugar a la proscripción política

\footnotetext{
37 Para todas las referencias al proyecto de Ley original enviado por Perón y Taiana al congreso, véase Argentina (1974a).
} 
El ocaso de la izquierda peronista en la Universidad de Buenos Aires: internas y debates ante la Ley Taiana 1973 - 1974

Nicolás Dip

en la universidad. En relación a este punto, también se consideraba necesario precisar la idea de "alteración del orden público" como causante de intervención de las casas de estudio, además de asentar que ésta no pudiera ser realizada por el poder ejecutivo, sino por el congreso (Art. 50ㅇ). Finalmente, la última modificación propuesta era anular el artículo que posibilitaba exigir estudios complementarios o cursos de capacitación antes de aceptar a alumnos a determinadas facultades, departamentos o carreras, porque eso podría dificultar el ingreso irrestricto (Art. 35으).

El 29 de enero representantes de las agrupaciones universitarias ya habían concurrido al congreso a exponer sus puntos de vista. Había asistido Ventura en representación de la JUP, Talento por la FULNBA y Ricardo Sidicaro, otro ex CN que era secretario académico de la Facultad de Filosofía y Letras, por ADUP. ${ }^{38}$ Sin embargo, cuando finalmente el 14 de marzo se aprobó la ley universitaria 20.654 en la Cámara de Diputados con 142 votos a favor y sólo 15 en contra, los legisladores del FREJULI no tuvieron en cuenta ninguna de las propuestas de la JUP y ADUP. Los principales cambios a la normativa en su tratamiento legislativo procedieron del radicalismo y del mismo oficialismo. ${ }^{39}$ Por petición de la UCR, se aceptó que el rector fuera elegido por las propias universidades y no por el poder ejecutivo como indicaba el proyecto original, aunque la representación de los distintos claustros en los órganos de gobierno continuó en proporción desigual: 60 por ciento para los docentes, 30 estudiantes y 10 no docentes (Art. 19으 y 33으). En este tema, es relevante tener en cuenta que la normativa resultante no sólo garantizaba el co-gobierno, sino que confería a las universidades autonomía académica junto a una autarquía administrativa, económica y financiera (Art. 3o).

\footnotetext{
38 Según el diario de sesiones del congreso, 57 organismos, instituciones o personas presentaron trabajos o propuestas relacionadas con la ley universitaria. Además, se realizó una reunión con 24 partidos políticos el 21 de enero de 1974 y otra con organizaciones universitarias el 29 de enero. A su vez, se presentaron cuatro proyectos de ley aparte del oficial. Las universidades nacionales también elevaron sus propuestas, así como muchas de sus facultades, centros de estudiantes, agrupaciones docentes y no docentes (ARGENTINA, 1974b).

${ }^{39}$ La composición del congreso luego del 25 de mayo de 1973 fue la siguiente: en la Cámara de Senadores, el FREJULI contaba con 44 de un total de 69 miembros. En segundo lugar, la UCR con 12 senadores y por último una serie de partidos provinciales. En la Cámara de Diputados, el FREJULI también tenía la mayoría absoluta con 144 miembros sobre un total de 243, mientras la UCR tenía 51 diputados. Los bloques de ambas cámaras del FREJULI estaban compuestos por el PJ, el Movimiento de Integración y Desarrollo, el Partido Conservador Popular y el Partido Popular Cristiano (FRIEDEMANN, 2015, p. 316-366).
} 
El ocaso de la izquierda peronista en la Universidad de Buenos Aires: internas y debates ante la Ley Taiana 1973 - 1974

Nicolás Dip

La otra modificación importante al proyecto de ley original provino del oficialismo, quien generalizó como una prohibición para todos los claustros de la universidad la cláusula que permitía la remoción de docentes por "proselitismo político partidario" o difundir "ideas contrarias al sistema democrático" (Art. 5o). Este punto renovaba el carácter restrictivo de la primera ley universitaria del peronismo (13.031) y de la normativa de Onganía para las casas de estudio (17.245). ${ }^{40}$ A esto se sumaba que el texto legal que aprobó el congreso finalmente dio continuidad a la resolución que permitía la intervención de las casas de estudio por el poder ejecutivo en casos de "alteración grave del orden público", "conflicto insoluble", "subversión con los podes de la Nación", entre otros (Art. $510)$.

Si bien la Ley Taiana fue aprobada por unanimidad en el senado y tuvo escasos votos en contra en la de diputados, los artículos 5o y 510 provocaron críticas en algunos legisladores del radicalismo, la Alianza Popular Revolucionaria (APR) y del peronismo. ${ }^{41}$ Entre estos últimos, estaban Leonardo Bettanin, Miguel Zavala Rodríguez y Rodolfo Ortega Peña. Los tres ingresaron a la cámara un día antes de la aprobación de la Ley Taiana porque ocho diputados de la JP Regionales habían renunciado a sus bancas para no acatar la directiva de Perón de votar las reformas al Código Penal que endurecía las penas por delitos políticos. ${ }^{42}$ Bettanin y Zavala Rodríguez pertenecían al sector juvenil vinculado a Montoneros. El primero había militado en los Comandos Estudiantiles Peronistas (CEP), uno de los grupos fundadores de la JUP. Por otro parte, Ortega Peña estaba vinculado al Peronismo de Base y dirigía Militancia Peronista para la Liberación, una revista crítica del gobierno que había publicado varias notas en defensa del rectorado de Puiggrós y el decanato de Kestelboim. ${ }^{43}$ Esto no era casual, ya que

\footnotetext{
40 El artículo 40 de la ley 13.031 establecía: "Los profesores y los alumnos no deben actuar directa, ni indirectamente en política, invocando su carácter de miembros de la corporación universitaria"; mientras el artículo 10 del decreto-ley 17.245 indicaba: "Prohíbase en los recintos universitarios, toda actividad que asuma formas de militancia, agitación, propaganda, proselitismo o adoctrinamiento de carácter político" (MIGNONE, 1998, p. 27-46).

${ }^{41}$ La APR había llevado la fórmula Alende-Sueldo en la primera campaña presidencial de 1973. Estaba compuesta por el PC, el Partido Revolucionario Cristiano, el Partido Intransigente y la Unión del Pueblo Argentino. Era la tercera fuerza política con representación en la Cámara de Diputados. En ese momento, votó en contra de la ley universitaria.

${ }^{42}$ Los ocho renunciantes fueron Rodolfo Vittar, Roberto Vidaña, Carlos Kunkel, Armando Croatto, Santiago Díaz Ortiz, Diego Muñiz Barreto, Jorge Gleller y Aníbal Iturrieta (HOY..., 1974).

${ }^{43}$ Tras su conocida jura - "la sangre derramada no será negociada"- Ortega Peña reemplazó a uno
} 
El ocaso de la izquierda peronista en la Universidad de Buenos Aires: internas y debates ante la Ley Taiana 1973 - 1974

Nicolás Dip

Ortega Peña había tenido cargos de gestión en la UNPBA e incluso había sido profesor de la Facultad de Filosofía y Letras y Derecho, hasta que fue apartado a fines de 1973 por aplicársele la ley de prescindibilidad a petición de Taiana. ${ }^{44}$

Los recién incorporados Bettanin y Zavala Rodríguez votaron la ley con el resto del bloque del FREJULI, pero mostraron su disconformidad con el artículo 50.45 El segundo de ellos reconoció durante el debate en el congreso que la ley contemplaba avances y demandas de la juventud universitaria. Aunque le parecía "de más e innecesario" hablar de "proselitismo" dado que la educación tiene siempre un trasfondo político y que toda política se desarrolla desde un interés concreto. ${ }^{46}$ Por su parte, desde su bloque unipersonal, Ortega Peña expresó una posición más crítica y votó en contra de la ley, aludiendo a su experiencia como “alumno, egresado, profesor universitario y como prescindido". A su entender, la normativa no cumplía con el "programa de liberación" elegido por el pueblo el 11 de marzo de 1973, ya que la prohibición de "actividades proselitistas" del artículo 5o podía llevar a proscribir cualquier actividad política en la universidad. También acusaba al ejecutivo de mantener una "grave contradicción" porque en la nueva ley de asociaciones profesionales se había derogado la normativa anterior que excluía la política en los sindicatos. Más polémico aún le parecía el artículo 510 dada la "peligrosísima" posibilidad de que el ejecutivo interviniera las universidades por decreto aludiendo a la idea de "subversión", un concepto tan "lato" y "ambiguo" que podía prestarse a cualquier interpretación. Finalmente,

de los diputados renunciantes de la JP, pero en lugar de integrarse al bloque del FREJULI por el que resultó electo, decidió conformar un bloque unipersonal: "bloque de la base" (CELESIA; WAISBERG, 2013, p. 257-259). También puede consultarse (ORTEGA..., 1974).

${ }^{44}$ La ley de prescindibilidad fue aprobada en octubre de 1973. La normativa autorizaba a dejar cesante a personal del Estado a criterio de las autoridades de cada dependencia y prohibía que los afectados volvieran a ingresar a la administración pública durante cinco años. Taiana decidió aplicarla para los cargos que tenían Ortega Peña y Duhalde en las facultades de Derecho y Filosofía y Letras. Esto en gran parte se debía a la posición crítica al gobierno de la revista Militancia Peronista para la Liberación. Villanueva, Kestelboim, la JUP y ADUP intentaron oponerse, aunque finalmente fueron separados de sus cargos (BUFANO; TEXIDÓ, 2015, p. 165166).

${ }^{45}$ Ambos al poco tiempo serían separados del bloque del FREJULI por una petición de Alberto Brito Lima, el jefe del Comando de Organización (POR MOCIÓN..., 1974).

${ }^{46}$ Todas las referencias al debate parlamentario corresponden a los diarios de sesiones de la Cámara de Senadores y de la Cámara de Diputados (ARGENTINA, 1974c; 1974d) y a Buchbinder (2014). 
Ortega Peña sentenciaba que si era sancionada la ley traería "consecuencias casi inmediatas" en la medida que el "estudiantado reaccione".

Cuando se aprobó la Ley Taiana el 14 de marzo de 1974, todos los interventores de las universidades nacionales presentaron sus renuncias, incluidos los delegados de las facultades y Villanueva, el secretario general a cargo del rectorado de la UNPBA desde la renuncia de Puiggrós. Según la flamante legislación, el poder ejecutivo debía designar nuevos decanos y rectores “normalizadores" para que en el plazo de un año las casas de estudio funcionaran de acuerdo a la nueva normativa. Al día siguiente, la JUP emitió un documento donde pedía que continúen en el cargo los funcionarios que venían desempeñándose hasta ese momento. A su vez, llamaba al estudiantado a movilizarse para impedir que la ley universitaria sea "instrumentada" por "sectores infiltrados" del gobierno que buscaban acabar con la política de “reconstrucción universitaria” iniciada por Puiggrós y seguida por Villanueva (LA UNIVERSIDAD..., 1974; LA JUP..., 1974) ¿Por qué ahora la JUP sentía como amenaza una normativa que reconocía buena parte de sus demandas en relación a la organización de la universidad? Este posicionamiento se explica por el contexto político particular de aquel entonces y porque las modificaciones introducidas a último momento a la ley lesionaban una concepción central de su ideario en relación al papel del estudiante en la universidad.

En relación al primer punto, no debe perderse de vista que la ley universitaria fue sancionada en un momento donde se profundizó el desplazamiento de actores vinculados a la izquierda peronista en distintas áreas de gobierno. En enero, Oscar Bidegain había sido obligado a renunciar a su cargo de gobernador de la provincia de Buenos Aires luego del asalto del ERP a una guarnición del ejército en la ciudad de Azul. Mientras que en febrero fue derrocado el primer mandatario de Córdoba, Ricardo Obregón Cano, mediante una asonada policial encabezada por Antonio Navarro (BONAVENA, 2012; SERVETTO, 2010). Además, casi en simultáneo a la sanción de la Ley Taiana fueron sancionadas un conjunto de normas que afectaban derechos y libertades públicas. A fines de 1973, se habían aprobado la ley de asociaciones profesionales y la de prescindibilidad. La primera aseguraba a las centrales sindicales la 
El ocaso de la izquierda peronista en la Universidad de Buenos Aires: internas y debates ante la Ley Taiana 1973 - 1974

Nicolás Dip

posibilidad de intervenir las seccionales locales de los gremios y la segunda cesantear en el sector público de manera arbitraria. A ello se sumó la reforma del Código Penal en enero de 1974, el cual incrementó las penas por delitos políticos (FRANCO, 2012, p.89). En paralelo, la organización paraestatal Triple A había comenzado hacer públicas sus acciones, como en el atentando contra el senador radical Hipólito Solari Irigoyen a fines del año anterior. En su "lista negra" de "enemigos a exterminar" también estaba el mismo Puiggrós.

En cuanto al segundo punto, la Ley Taiana incluía una cláusula que limitaba la actividad política en la universidad y esto directamente lesionaba uno de los idearios centrales de la JUP. Si bien la agrupación liderada por Ventura reivindicó muchos puntos de la normativa, concebía a la participación política del estudiantado como condición ineludible para garantizar una presencia crítica que vinculara las problemáticas concretas de las casas de estudio con cuestiones políticas y sociales más amplias. En este tema era tributaria del Manifiesto de FORJA a los estudiantes de la Universidad de Buenos Aires que había publicado Antropología 3er. Mundo en 1970 y que volvió a editar la revista Crisis en marzo de $1974 .{ }^{47}$ Como vimos, este documento llamaba a recuperar un ideario central atribuido a la Reforma y sintetizado en el lema: "el estudiante de la universidad es transfusión del pueblo en las aulas" (FORJA..., 1970, p.72) En esta cuestión, es sugestivo que durante el debate de la Ley Taiana la JUP no invocó la ley universitaria 13.031 del primer peronismo, como sí lo hicieron los sectores del movimiento que cuestionaban a la JP Regionales y Montoneros. La revista Las Bases, el órgano oficial del MNJ que resaltaba la figura del ministro López Rega, publicó en aquel entonces una gran cantidad de notas dedicadas a ese tema e incluso la CNU durante el debate parlamentario había acercado al presidente del bloque de senadores del FREJULI, José Humberto Martiarena, una serie de documentos que pedían elaborar la nueva ley en base a la de 1947 (UNIVERSIDAD,

\footnotetext{
47 Crisis fue una publicación de política y cultura editada en la ciudad de Buenos Aires, pero que contenía un staff compuesto por intelectuales, periodistas y escritores de Argentina y Uruguay. Cuando salió su primer número en mayo de 1973, Federico Vogelius era su director ejecutivo, Eduardo Galeano el director editorial y Julia Constenla la secretaria de redacción. El artista plástico Hermenegildo Sábat fue el ilustrador de los cuarenta números que aparecieron todos los meses hasta agosto de 1976. En sus páginas, participaron Aníbal Ford, Juan Gelman, Mario Benedetti y Rogelio García Lupo (SONDERÉGUER, 2011).
} 
El ocaso de la izquierda peronista en la Universidad de Buenos Aires: internas y debates ante la Ley Taiana 1973 - 1974

Nicolás Dip

1974). ${ }^{48}$ Justamente, el ordenamiento legal del primer peronismo había establecido que los universitarios sólo podían dedicarse a sus funciones específicas y no actuar directa ni indirectamente en política. La complejidad de la Ley Taiana radicó en que reconoció demandas de la izquierda peronista y el radicalismo, pero también abrió la puerta a los que buscaban acabar con la politización de las casas de estudio.

\section{La nueva noche de los bastones largos}

A la ruptura definitiva entre Perón y Montoneros en el acto del día del trabajador realizado el 1 de mayo de 1974, le siguió al mes siguiente la partida del viejo líder del peronismo. El 1 de julio a horas de anunciarse su muerte, la Secretaría de Prensa y Difusión de la Presidencia afirmó que el poder ejecutivo había aceptado a Solano Lima la renuncia a sus dos cargos: el de secretario general de la Presidencia y el de rector normalizador. El líder del Partido Conservador Popular no hizo públicos sus motivos (¿RENUNCIÓ..., 1974; LIMA..., 1974). Al poco tiempo, Taiana le pidió que continuase en la UNPBA. Entre idas y vueltas, Solano Lima obtuvo una licencia y Laguzzi, el decano de Farmacia referenciado con la JP Regionales, fue nombrado interinamente como rector normalizador. Finalmente, la dimisión de Solano Lima se hizo efectiva, con lo cual Laguzzi quedó al frente de la casa de estudio porteña, al ser nombrado por Taiana el 24 de julio ad-referéndum del poder ejecutivo (LIMA..., 1974; EL DOCTOR..., 1974; LAGUZZI..., 1974).

Sin embargo, la asunción de Isabel Perón volvió el panorama más adverso aún para la izquierda peronista. El 14 de agosto fue reemplazado Taiana por Oscar Ivanissevich en el Ministerio de Cultura y Educación (HAY..., 1974). El flamante funcionario era un representante del nacionalismo católico de derecha con una extensa trayectoria tras de sí. Había sido rector interventor de la UBA por un breve lapso en 1946 y ocupado el Ministerio de Educación durante el primer peronismo. Desde entonces pensaba que los estudiantes no debían hacer política

\footnotetext{
48 Además, pueden consultarse en la misma revista las siguientes notas sobre universidad (OTRO...,1973; LA REFORMA..., 1973; EL PERONISMO..., 1973; LAS LEYES..., 1973; VI CONGRESO..., 1973; GRAVE..., 1973; UNIVERSIDAD..., 1974; LA HORA..., 1974).
} 
y se declaraba enemigo de la Reforma del '18 (BESOKY, 2015, p. 283). El mismo día de su designación, la FULNBA y la Federación de Trabajadores Docentes Universitarios de la Universidad de Buenos Aires (FATDUBA) realizaron una movilización y ocuparon facultades pidiendo que se garantizara la continuidad de Laguzzi, pero también la de Taiana. A su vez, rechazaron la posible designación de Rodolfo Tecera del Franco como rector y sostuvieron que iban a continuar con las "tomas" para garantizar el normal funcionamiento de las casas de estudio y que éstas no sean atacadas por "grupos reaccionarios" (FUERON..., 1974c; DESPLIEGUE..., 1974).

A esto se sumaron nuevos alejamientos de funcionarios de la UNPBA cercanos a la JUP y ADUP. Luego de emprender una serie de acciones armadas, el 6 de septiembre Montoneros anunció su pasaje a la clandestinidad en una conferencia de prensa en la que Mario Firmenich fue acompañado por los distintos referentes de los frentes de masas de la JP Regionales, entre ellos estaba Ventura en representación de la JUP (MONTONEROS..., 1974). Esto desencadenó la inmediata renuncia del decano de la Facultad de Derecho. El propio Kestelboim difundió públicamente los motivos de su renuncia en un comunicado donde afirmaba que se "negaba a ser instrumento de esa política" y que no podía aceptar que la JUP, "una de las corrientes principales que sostuvo su gestión", le declarara la "guerra" al gobierno (RENUNCIÓ..., 1974). El 9 de septiembre, el rectorado de la UNPBA decidió aceptar su dimisión y nombró interinamente a Leonardo Franco, un docente de la facultad que había participado con Kestelboim en la Asociación Gremial de Abogados y en la Agrupación de Abogados Peronistas (UBA, 1974).

Desde la asunción de Ivanissevich, se venía vaticinando una posible intervención de la UNPBA. La Causa Peronista, el órgano de prensa oficial de Montoneros y la JP Regionales que reemplazó a El Descamisado luego de su clausura, publicó una nota a principios de septiembre en la que acusaba al gobierno de Isabel de preparar una "nueva noche de los bastones largos" (PREPARAN..., 1974). El propio ministro de Educación se encargó de despejar esta cuestión. En un discurso que brindó en el Teatro Colón el 10 de septiembre por el día del maestro, sostuvo que el artículo 5o de ley universitaria, el cual prohibía 
el "proselitismo político partidario" y las "ideas contrarias al sistema democrático", no se estaba cumpliendo. Además, advirtió que "estaban dadas las causas" establecidas por esa misma normativa para intervenir las universidades. Para Ivanissevich, los estudiantes no estaban ocupando las facultades para protegerlas, sino que las usaban para la "subversión” y para atacar directamente la "jerarquía del Estado y la integridad de la República”. A su entender, lo que se imponía era el cierre de las universidades para "asearlas, ordenarlas y normalizarlas", dado que no se estaba ante un "conflicto universitario", sino ante una "batalla a muerte" contra una "conjura internacional" que pretendía "destruir la patria de Perón y la fe cristiana" (IVANISSEVICH, 1974).

Como última señal de resistencia, el 14 de septiembre el rector Laguzzi y el secretario general Villanueva convocaron en una conferencia de prensa a los tres claustros universitarios -docentes, estudiantes, no docentes- a un plebiscito obligatorio a realizarse el 19 y 20 de ese mismo mes en todas las casas de estudio, con el fin de que se pronunciaran en relación a si avalaban o no la política universitaria impulsada desde la asunción de Puiggrós hasta la fecha. A su vez, acusaban a Ivanissevich de tener una concepción similar a los "adictos a las dictaduras militares" por su rechazo a la participación política universitaria (HABRÁ..., 1974; EL NUCLEAMIENTO..., 1974). Finalmente, el plebiscito no pudo Llevarse adelante debido a que a los tres días de la conferencia de prensa fue intervenida la casa de estudio porteña con el decreto 865 de la presidenta Isabel Perón. En sus considerandos, la medida afirmaba que "era público y notorio" que estaban dadas las causales de intervención previstas por el artículo 510 de ley 20.654, entre las que se encontraban la "alteración del orden público" y la “subversión” (ARGENTINA, 1974e). Para llevar adelante la tarea, se designó a Alberto Ottalagano como nuevo rector interventor, un abogado y doctor en filosofía que había sido asesor de Perón en su último mandato y se asumía abiertamente como fascista y antimarxista. En su adolescencia, había sido delegado de la Alianza Libertadora Nacionalista y durante los años del primer peronismo había intervenido en la fundación de la Confederación General Universitaria (OTTALAGANO, 1983). 
El ocaso de la izquierda peronista en la Universidad de Buenos Aires: internas y debates ante la Ley Taiana 1973 - 1974

Con el arribo de Ivanissevich y Ottalagano dejó de nombrarse a la casa de estudio porteña como la "Universidad Nacional y Popular de Buenos Aires". Sin embargo, sería un error entender su llegada como un punto de quiebre total, ya que la designación de ambos tenía elementos de continuidad con el proceso abierto a partir de la sanción de la Ley Taiana. La aprobación de esta normativa había terminado otorgando herramientas legales para combatir al activismo político y creado condiciones para el fortalecimiento de actores que pensaban que el "peligro subversivo" debía ser erradicado con métodos legales e incluso extra legales. En el caso de la UBA, esta última cuestión resultó paradigmática si se tiene en cuenta la represión sufrida por la militancia estudiantil y el desplazamiento de las autoridades y los docentes de la izquierda peronista.

Estos últimos sufrieron atentados al poco tiempo de ser nombrado Ivanissevich. El 4 de septiembre fueron colocados explosivos en la casa de Adriana Puiggrós y el 7 en la de Laguzzi, lo cual dejó como saldo la muerte de su hijo de seis meses (SOLIDARIDAD..., 1974). Un día antes de este hecho, la revista El Caudillo publicó una nota titulada "Cuentas claras política espesa”. En ella se criticaba a Solano Lima por "haber entregado todo al marxismo loco de Laguzzi y sus adláteres". Además de responsabilizar a éste y a Adriana Puiggrós - "una marxista de triste apellido"- de haber convertido a la universidad en un "nido subversivo" y en una "escuela del ridículo político". A su entender, la única solución era una "cirugía mayor" para acabar de una vez con el "último bastión" que conservaba "la Tendencia” (CUENTAS..., 1974a). Este órgano de prensa de la derecha peronista era dirigido por Felipe Romero y financiado con publicidad del Ministerio de Bienestar Social que encabezaba López Rega, el líder de la Triple A. En su distribución y realización, colaboraban miembros de la CNU y de la Juventud Peronista de la República Argentina (JPRA). ${ }^{49}$

\footnotetext{
49 La JPRA fue Liderada por Julio Yessi, quien en 1973 había sido nombrado por Perón como representante de la JP en el Consejo Superior del MNJ, con el objetivo de aglutinar a los sectores juveniles diferenciados de Montoneros (BESOKY, 2016, p.213). Juan Alfredo Muciaccia, un ex militante del Movimiento Federal que conoció a Perón por intermedio de Yessi, era el secretario general. En una entrevista brindada a El Caudillo a fines de 1973, reconocía a la JPRA como un organización que pretendía institucionalizar la "revolución peronista" con "fanatismo", incluso llegando hasta las "últimas consecuencias” (REPORTAJE..., 1973).
} 
Cuando se hizo cargo Ottalagano del rectorado de la UBA declaró asueto y dejó cesantes a todos los decanos, funcionarios y docentes nombrados desde la asunción de Puiggrós (PROLONGAN..., 1974). Luego designó nuevas autoridades en las facultades: Mario José Framiñan en Odontología, José Penna en Ciencias Económicas, Jorge Antonio Antelo en Medicina, Lucas Tortoreli en Agronomía, Raúl Zardini en Ciencias Exactas y Rául Sánchez Abelenda en Filosofía y Letras. Este último recorrió las instalaciones de su facultad con una rama de olivo para exorcizar los “malos espíritus de Freud, Marx y Piaget” (PUIGGRÓS, 2003, p. 337). Mientras Zardini había sido uno de los decanos más cuestionados por el movimiento estudiantil en los años de la "Revolución Argentina", por ser defensor de los cupos y el examen de ingreso eliminatorio. En 1972, la revista Ciencia Nueva lo había caracterizado como "el decano de la inquisición" y de ser un “oscurantista anticomunista” (EL DECANO..., 1972).

Antes de la llegada de Ivanissevich y Ottalagano, la Triple A ya había amenazado a integrantes de la UNPBA e incluso asesinado a Ortega Peña el 31 de julio de 1974. Pero luego de sus designaciones, las intimidaciones se multiplicaron. El 20 de septiembre, después de asesinar a Julio Troxler -un antiguo militante de la resistencia peronista que había sobrevivido a la masacre de José León Suárez en 1956- la Triple A difundió una "lista negra" en la que figuraban Cámpora, Firmenich, Bettanin, Taiana, Villanueva y Laguzzi. Este clima llevó a muchos ex integrantes de la UNPBA a la decisión de abandonar el país, como en el caso de Rodolfo Puiggrós, su hija Adriana, Testa, Ibarlucía y Laguzzi.

El arribo de Ivanissevich y Ottalagano también implicó un oscuro panorama para los militantes estudiantiles. Desde la UBA, se desplegaron medidas con la finalidad de acabar con su activismo político. El 1 de noviembre, El Caudillo realizó una entrevista al teniente coronel Antelo, el interventor de Medicina, en la cual advertía a la "muchachada estudiantil" que la facultad "estaba para estudiar" y que toda otra actividad será dirigida "hacia donde corresponde" (FACULTAD..., 1974). A principios de octubre, luego de que Isabel firmara la ley antisubversiva, Ottalagano había creado un "cuerpo de celadores" bajo la dirección de Jaime Lemos, hombre de confianza de López Rega y funcionario del Ministerio de 
El ocaso de la izquierda peronista en la Universidad de Buenos Aires: internas y debates ante la Ley Taiana 1973 - 1974

Nicolás Dip

Bienestar Social (FRIEDEMANN, 2015, p. 425-437). ${ }^{50}$ Sus integrantes portaban armas de fuegos y vigilaban los pasillos de las facultades para que se cumpliera la prohibición de realizar cualquier tipo de asambleas o la aplicación de amonestaciones por participar en marchas o en huelgas (PROMULGÓSE..., 1974; SEÑALÓ..., 1974; ESTÁ..., 1974).

El decreto 865 que firmó Isabel para intervenir la UBA designaba a Ottalagano como interventor hasta el 31 de diciembre de 1974, por lo cual luego de esa fecha fue reemplazado por Julio Lyonnet. En los más de tres meses de gestión de Ottalagano fueron asesinados 15 estudiantes porteños (IZAGUIRRE, 2011). Un mes antes de su salida del rectorado, la FULNBA había aplazado la realización de los comicios estudiantiles "hasta que existan condiciones favorables" e intentado llevar adelante un plebiscito para pedir el relevo del ministro, el rector y los 11 decanos de las facultades. La respuesta del gobierno ante ese intento fue nuevamente la represión y el encarcelamiento de dirigentes estudiantiles. El 22 de noviembre fueron detenidos Ventura y Talento en Villa Devoto (TALENTO..., 1974). Luego de pasar unos meses en la cárcel, ambos partieron al exilio. Cuando Ottalagano abandonó la UBA, Ivanissevich estuvo a cargo del Ministerio de Educación hasta ser reemplazado en agosto de 1975 por Pedro Arrighi. La designación y el protagonismo de ambos deben ser entendidos en el contexto más amplio de una escalada de violencia política legal e ilegal, donde la supuesta lucha contra la subversión inauguró el terrorismo de Estado antes de la última dictadura militar.

\section{Conclusión}

En este trabajo intentamos contribuir a la bibliografía sobre la historia reciente de las universidades, los movimientos estudiantiles y los intelectuales que abordan el proceso de peronización en los años sesenta y setenta. Desde una mirada retrospectiva, podemos destacar como aporte del estudio que la

\footnotetext{
50 Como ley antisubversiva se conoció la Ley de Seguridad enviada por el poder ejecutivo al congreso el 25 de septiembre de 1974 y promulgada por Isabel Perón unos días después. La misma implicaba una fuerte constricción de la actividad política y violaba el derecho a huelga sancionado por la Constitución Nacional. También entre sus castigos previstos, se encontraba la suspensión de la ciudadanía y la expulsión del país. La dictadura de 1976 retomaría al pié de la letra toda la ley antisubversiva de 1974. (FRANCO, 2012, p. 118-119).
} 
politización y la partidización de la JUP y ADUP condujeron a una tensión irresoluble en el transcurso del último gobierno peronista; especialmente cuando se produjo el desencuentro entre el líder retornado del exilio y los sectores del movimiento que habían vinculado la oposición a la dictadura militar con la posibilidad de impulsar transformaciones más profundas. Desde su constitución, ambas agrupaciones universitarias pretendían atender las especificidades de las casas de estudio en el marco de dos referencias políticas: el gobierno peronista, al que procuraban aportarle políticas universitarias, y Montoneros, con el que seguirían el camino de la "guerra popular y prolongada". Cuando sus dos referentes entraron en conflicto, la JUP y ADUP terminaron descolocadas en su accionar político-universitario, debido a que ese mismo gobierno que decían defender instrumentó desde fines de 1973 distintas medidas para desplazar a sus funcionarios afines de la intervención de la UBA. A esto se sumó que la ley universitaria que habían discutido desde un principio con tanta expectativa, finalmente se aprobó en 1974 con dos artículos controvertidos (5ํy 510) que permitieron que la casa de estudio porteña fuera nuevamente intervenida, esta vez bajo sectores de la derecha peronista. De esta manera, durante el gobierno de Isabel Perón se implementó una concepción contraria a la de la izquierda peronista, sobre todo en relación al papel político del estudiante en la universidad. Mientras esta última lo consideraba una correa de trasmisión para vincular la problemática académica con cuestiones revolucionarias más amplias, la derecha peronista lo imaginaba como un foco infeccioso que promovía la subversión.

En síntesis, este trabajo espera haber demostrado que el ocaso de la UNPBA y de la peronización de izquierda estuvo directamente relacionado a la correlación de fuerzas que expresó la sanción de la Ley Taiana. A modo de cierre, señalamos algunas problemáticas pendientes que pueden profundizar investigaciones futuras para mostrar nuevas aristas del caso estudiado. Si bien en este artículo reconstruimos el respaldo de la JUP y ADUP a la gestión de Puiggrós como sus debates ante la sanción de la normativa, todavía resta un análisis más pormenorizado sobre cómo se desarrolló esta experiencia de politización en cada una de las facultades porteñas, haciendo hincapié en la 
El ocaso de la izquierda peronista en la Universidad de Buenos Aires: internas y debates ante la Ley Taiana 1973 - 1974

Nicolás Dip

trayectoria y la perspectiva político-académica de los integrantes de cada institución. Asimismo, nos parece necesario seguir fortaleciendo el estudio sobre la cuestión universitaria en el amplio conglomerado de la izquierda argentina de los años setenta. El análisis de grupos escasamente explorados como el MOR o la Juventud Radical Revolucionaria, puede contribuir a mostrar distintas facetas de la partidización de un heterogéneo conglomerado de sectores docentes y estudiantiles que no se reducía al peronismo e incluía a agrupaciones vinculadas al Partido Comunista y a la UCR.

\section{Referências}

A PUIGGRÓs le fue exigida la renuncia y los delegados de facultades lo apoyan. La Opinión, Buenos Aires, 2 oct. 1973.

ACHA, Omar. La Nación Futura: Rodolfo Puiggrós en las encrucijadas argentina del siglo XX. Eudeba: Buenos Aires, 2006.

ADUP. Documento presentado por la Juventud Peronista al compañero Cámpora. Política universitaria. Envido, n. 8, mar. 1973

AGOGLIA, reemplazante de Puiggrós. La Razón, 25 oct. 1973e.

ARGENTINA. Decreto n. 35, de 29 mayo 1973. Boletín Oficial de la República Argentina, Buenos Aires, n. 22705, Año LXXXI, viernes 13 jul. 1973a.

ARGENTINA. Decreto n. 1.574, de 02 oct. 1973, Boletín Oficial de la República Argentina, Buenos Aires, n. 22.738, Año LXXXI, martes 6 nov. $1973 b$.

ARGENTINA. Régimen de universidades nacionales - Mensaje y proyecto de ley del Poder Ejecutivo. Buenos Aires: Cámara de Senadores de la Nación, 65a reunión, continuación de la 15a Sesión Extraordinaria, p. 3605-3632, 4-5 mar. 1974a.

ARGENTINA, Diario de Sesiones, “Inserciones”. Buenos Aires: Cámara de Senadores de la Nación, 66a reunión, 15a sesión extraordinaria, p. 3810-3825, 7-8 mar. 1974b.

ARGENTINA. Diario de sesiones. Buenos Aires: Cámara de Senadores, 66a reunión, 16a sesión extraordinaria, p. 3675-3809, 7-8 mar 1974c.

ARGENTINA. Diario de sesiones. Buenos Aires: Cámara de Diputados, 65a Reunión, continuación de la 3a sesión extraordinaria, p. 6295-6369, 13-14 mar. 1974d. 
ARGENTINA, 1974. Decreto n. 865, de 17 sept. 1974. Boletín Oficial de la República Argentina, Buenos Aireses, n. 22999, Año LXXXII, lunes 23 sept. 1974e.

BARLETTA, Ana María. Peronización de los universitarios (1966-1973). Pensamiento Universitario, n. 9, 2001.

BARLETTA, Ana María. Una izquierda universitaria peronista (1968-1973). Prismas, UNQUI, n. 6, 2002.

BARTOLETTI, Julieta. Montoneros: de la movilización a la organización. Un caso paradigmático de militarización. 2010. Tesis (Doctorado en Ciencia Política) Universidad Nacional de San Martín, Buenos Aires, 2010.

BASES de la JUP. La Nación, Buenos Aires, 24 de abr. 1973.

BERNETTI, Jorge. El peronismo de la victoria. Buenos Aires: Colihue, 2011.

BESOKY, Juan Luis. La derecha peronista. Prácticas políticas y representaciones (1943-1976). 2016. Tesis (Doctorado en Ciencias Sociales) - Facultad de Humanidades y Ciencias de La Educación, Universidad Nacional de La Plata, La Plata, 2016.

BONAVENA, Pablo. Guerra contra el campo popular en los setenta. Juan Domingo Perón, la depuración ideológica y la ofensiva contra los gobernadores. In: IZAGUIRRE, Inés. Lucha de clases, guerra civil y genocidio en la Argentina 1973-1983. Buenos Aires: Eudeba, 2012

BONAVENA, Pablo. Los estudiantes universitarios peronista. Del golpe de Onganía a los «azos» del '69. In: JORNADAS DE ESTUDIO Y REFLEXIÓN SOBRE EL MOVIMIENTO ESTUDIANTIL ARGENTINO Y LATINOAMERICANO, 5., 2014, Mar del Plata. Anais [...]. Mar del Plata: Universidad Nacional de Mar del Plata, 2014.

BUCHBINDER, Pablo. Historia de las universidades argentinas. Buenos Aires: Sudamericana, 2005.

BUCHBINDER, Pablo. La universidad y el tercer peronismo: notas sobre el debate parlamentario en torno a la Ley Taiana. In: MILLÁN, Mariano (comp.). Universidad, política y movimiento estudiantil en Argentina: entre la revolución libertadora y la democracia del '83. Buenos Aires: Final Abierto, 2014.

BUFANO, Sergio Bufano; TEXIDÓ, Lucrecia. Perón y la Triple A: Las 20 advertencias a Montoneros. Buenos Aires: Sudamericana, 2015.

CÁMPORA, Héctor. La revolución justicialista. Buenos Aires: Eudeba, 1973. 
CARUSO, Valeria; CAMPOS, Esteban; VIGO, Mariano; ACHA, Omar. La izquierda peronista: una categoría útil para el análisis histórico". Historiografías, Zaragoza, n. 14, p. 68-90, 2017.

CELESIA, Felipe; WAISBERG, Pablo. La Ley y las armas: biografía de Rodolfo Ortega Peña. Buenos Aires: Aguilar, 2013.

CREA expectativa la movilización peronista. La Nación, Buenos Aires, 22 abr. 1973.

CREAN una comisión que redactará ley universitaria. La Opinión, Buenos Aires, 12 jun. 1973.

CUENTAS claras y política espesa. El Caudillo, Buenos Aires, n. 42, 6 sept. 1974.

DE RIZ, Liliana. Retorno y derrumbe: el último gobierno peronista. Buenos Aires: Hyspamérica, 1981.

DESFAVORABLE reacción de estudiantes reformistas. Actúa la comisión redactora de una ley. La Opinión, Buenos Aires, 22 jun. 1973.

DESIGNÓSE interventor universitario. La Prensa, Buenos Aires, 28 nov. 1973.

DESPLIEGUE policial para impedir el acto de la FULNBA. Noticias, 15 ago. 1974.

DISCUTE la JUP su apoyo a la gestión de Agoglia. La Opinión, Buenos Aires, 26 oct. 1973.

DISPUTAS ideológicas en la Universidad. La Opinión, Buenos Aires, 19 jun. 1973.

DRÁSTICAS instrucciones a los dirigentes del Movimiento para que excluyan todo atisbo de heterodoxia marxista. La Opinión, Buenos Aires, 2 oct. 1973.

EL DECANO de la inquisición. Ciencia Nueva, Buenos Aires, n. 16, mayo 1972.

EL DOCTOR Lima deja hoy la Universidad de Buenos Aires. La Opinión, Buenos Aires, 25 jul. 1974.

EL NUCLEAMIENTO radical aspira a preservar la actividad académica. La Opinión, Buenos Aires, 17 sept. 1974.

EL PERONISMO abre auténticamente las aulas al pueblo. Las Bases, Órgano oficial del Movimiento Nacional Justicialista, Buenos Aires, n. 67, 7 nov. 1973. 
EL PROBLEMA Universitario. La Razón, Buenos Aires, 5 oct. 1973.

EL RESPALDO del estudiantado. Siete Días, Buenos Aires, 20 jul. 1973.

ESTÁ contemplada la desaparición de los cuerpos de celadores en las Facultades. La Opinión, Buenos Aires, 31 dic. 1974.

FACULTAD de Medicina: aquí también llegó el peronismo. El Caudillo, Buenos Aires, n. 48, 1 nov. 1974.

FORJA y la Universidad. Antropología 3.er Mundo, Buenos Aires, n. 4, sept. 1970.

FORJA y el problema universitario. Crisis, Buenos Aires, n. 11, mar. 1974.

FRANCO, Marina. Un enemigo para la nación. Orden interno, violencia y

"subversión" 1973-1976. Buenos Aires: FCE, 2012.

FRIEDEMANN, Sergio. La izquierda peronista de los años sesenta como fenómeno argentino de la llamada nueva izquierda. Tempo \& Argumento, Florianópolis, v. 10, n. 24, p. 484-509, 2018.

FUA - La Plata define los alcances de su apoyo a las autoridades universitarias. La Opinión, Buenos Aires, 16 jun. 1973.

FUERON ocupadas las facultades anoche. La Nación, Buenos Aires, 14 ago. 1974.

GALIMBERTI dijo cómo serán las milicias. La Nación, Buenos Aires, 23 abr. 1973.

GRAVE renuncia: atacan al gobierno del pueblo. Las Bases, Órgano oficial del Movimiento Nacional Justicialista, Buenos Aires, n. 73, 19 dic. 1973.

HABLA el interventor en la universidad. Reportaje exclusivo a Ernesto Villanueva. Noticias, Buenos Aires, 28 nov. 1973

HABRÁ un plebiscito en la Universidad. La Nación, Buenos Aires, 14 sept. 1974.

HACIA la universidad de los trabajadores. Los estudiantes ipor la ley! Las Bases, Órgano oficial del Movimiento Nacional Justicialista, Buenos Aires, n. 85, 12 mar. 1974c.

HAY un compás de espera en el Problema Universitario. La Razón, Buenos Aires, 6 oct. 1973.

HAY nuevo gabinete. Noticias, Buenos Aires, 15 ago. 1974. 
HOY entran los ocho diputados. Reemplazarán a los que renunciaron por oponerse a la ley represiva. Noticias, Buenos Aires, 13 mar. 1974.

HOY inicia sus tareas la comisión que redactará la futura ley universitaria. La Opinión, Buenos Aires, 15 jun. 1973.

IVANISSEVICH, OSCAR. Mensaje de su Excelencia el señor Ministro de Cultura y Educación doctor Oscar Ivanissevich. 10 de setiembre de 1974. Buenos Aires: Ministerio de Cultura y Educación, Centro Nacional de Documentación e Información Educativa, 1974.

IZAGUIRRE, Inés. La Universidad y el Estado terrorista. La Misión Ivanissevich. Conflicto Social, UBA, Buenos Aires, n. 5, p. 287-303, 2011.

JORGE Taiana delimitó las atribuciones de los interventores de las casas de estudio. La Opinión, Buenos Aires, 26 jun. 1973.

JUP. Juventud Universitaria Peronista. Envido, Buenos Aires, n. 9, mayo 1973a.

\section{JUP. El peronismo en la universidad. Abril 1973. Aportes para la nueva}

universidad, Buenos Aires: Secretaría de Planeamiento; UNPBA, n. 1, jul. 1973b.

\section{LA CUESTIÓN de la autonomía es fundamental para la JRR. El Cronista}

Comercial, Buenos Aires, 20 feb. 1974.

LA CONSIGNA del imperialismo. Liquidar la Universidad antes del 12 de octubre. El Descamisado, Buenos Aires, n. 19, 26 sept. 1973.

LA ELABORACIÓN de la nueva ley motiva polémicas en las casas de estudios. La Opinión, Buenos Aires, 2 ago. 1973.

LA FULNBA no acepta que la ley sea sancionada durante el receso de verano y exige un debate previo. Noticias, Buenos Aires, 29 dic. 1973.

LA GESTIÓN del rector Puiggrós suscita una ofensiva continuista. La Opinión, Buenos Aires, 13 jun. 1973.

LA HORA del país real ha llegado. Las Bases, Órgano oficial del Movimiento Nacional Justicialista, Buenos Aires, n. 79, 5 feb. 1974b.

LA INTERVENCIÓN en la Universidad. La Nación, Buenos Aires, 31 mayo 1973.

LA JUP convocó a la movilización. En un documento, llama a los estudiantes a sostener en sus cargos a las actuales autoridades. Noticias, Buenos Aires, 16 mar. 1974. 
LA JUP denuncia una ofensiva reaccionaria que intenta frenar la Liberación Nacional. El Descamisado, Buenos Aires, n. 20, 2 oct. 1973.

LA JUP rechaza a Agoglia como nuevo interventor. La Opinión, Buenos Aires, 27 oct. 1973.

LA JUVENTUD Universitaria Peronista tomó el Rectorado y ocupó todas las Facultades. La Razón, Buenos Aires, 3 oct. 1973.

LA LEY Universitaria. Taiana respondió a las críticas del radicalismo. Noticias, Buenos Aires, 19 feb. 1974.

LA REFORMA: sus conquistas gremiales. Su instrumentación política. Las Bases. Órgano oficial del Movimiento Nacional Justicialista, Buenos Aires, n. 65, 24 oct. 1973b.

LA UNIVERSIDAD: La JUP apoya la ley. Noticias, Buenos Aires, 24 feb. 1974.

LA UNIVERSIDAD al borde de la opción: liberación o continuismo gorila. El Descamisado, Buenos Aires, n. 43, 12 mar. 1974.

LAS LEYES peronistas. Las Bases, Órgano oficial del Movimiento Nacional Justicialista, Buenos Aires, n. 68, 14 nov. 1973d.

LA REINCORPORACIÓN de los sancionados aumenta la base de apoyo de Puiggrós. La Opinión, Buenos Aires, 12 jun. 1973.

LAGUZZI afirmó que no variará la política universitaria. La Opinión, Buenos Aires, 26 jul. 1974.

LEY universitaria: piden postergarla. Noticias, Buenos Aires, 21 feb. 1974.

LIMA abandonaría indeclinablemente la Universidad. La Opinión, Buenos Aires, 6 jul. 1974.

LIMA se va, nomás. Noticias, Buenos Aires, 25 jul. 1974.

LINEAMIENTOS generales para la elaboración de la ley universitaria. Aportes para la Nueva Universidad, Secretaría de Planeamiento, UNPBA, Buenos Aires, n. 3, ago. 1973.

LOS ESTUDIANTES peronistas ocuparon ayer todas las facultades de la UBA. La Opinión, Buenos Aires, 13 jul. 1973. 
MAÑANA se anunciará la creación de la rama universitaria de la JP. La Opinión, Buenos Aires, 22 abr. 1973.

MANIFESTACIÓN estudiantil en el Congreso. La Nación, Buenos Aires, 21 febr. 1974.

MIGNONE, Emilio. Política y universidad: el Estado legislador. Buenos Aires: Lugar Editorial, 1998.

MILITANCIA PERONISTA PARA LA LIBERACIÓN. La Prensa y La Nación frente a la Universidad. Militancia Peronista para la Liberación, Buenos Aires, n 3, 27 jun. 1973a.

MILITANCIA PERONISTA PARA LA LIBERACIÓN. Universidad. Fin de la dependencia. Militancia Peronista para la Liberación, Buenos Aires, n. 7, 26 jul. 1973b.

MONTONEROS pasó a la resistencia activa. La Nación, Buenos Aires, 7 sept. 1974.

NO REEMPLAZA Agoglia a Puiggrós. La Razón, Buenos Aires, 27 oct. 1973.

OCUPARON anoche el Rectorado de la Universidad. La Opinión, Buenos Aires, 3 oct. 1973.

OTRO país, un país distinto y extraño. Las Bases, Órgano oficial del Movimiento Nacional Justicialista, Buenos Aires, n. 63, 10 oct. 1973a.

OTTALAGANO, Alberto. Soy fascista. ¿Y qué? Una vida al servicio de la patria. Buenos Aires: ROCA Producciones, 1983.

PERDÍA, Roberto. Montoneros: el peronismo combatiente en primera persona. Buenos Aires: Planeta, 2013.

PEREL, Pablo, RAÍCES, Eduardo; PEREL, Martín. Universidad y dictadura. Derecho, entre la liberación y el orden (1973-1983). Buenos Aires: Ediciones del CCC, 2007.

PERÓN no solicitó la renuncia de Puiggrós. La Opinión, Buenos Aires, 4 oct. 1973.

POR MOCIÓN de Brito Lima diputados de la JP fuera del bloque. Noticias, Buenos Aires, 21 mar. 1974.

POSICIÓN de la JUP ante la ley universitaria. La Nación, Buenos Aires, 24 febr. 1974. 
PREPARAN una nueva noche de los bastones largos. La Causa Peronista, Buenos Aires, n. 9, 3 sept. 1974.

PRIMER Congreso Nacional de la Juventud Universitaria Peronista. El Descamisado, Buenos Aires, n. 17, 1 sep. 1973a.

PRIMER intento opositor en la universidad local. La Opinión, Buenos Aires, 12 jun. 1973b.

PROLONGAN en siete días el asueto universitario. La Nación, Buenos Aires, 21 sept. 1974.

PROMULGÓSE la ley antisubversiva. La Nación, Buenos Aires, 1 oct. 1974.

PUIGGRÓS crea una nueva comisión. La Opinión, Buenos Aires, 27 jun. 1973.

PUIGGRÓS, Adriana. El lugar del saber: conflictos y alternativas entre educación, conocimientos y política. Buenos Aires: Galerna, 2003.

PUIGGRÓS, Adriana. Rodolfo Puiggrós: retrato familiar de un intelectual militante. Buenos Aires: Taurus, 2010.

RECALDE, Aritz. La Universidad de Buenos Aires en la década de 1970: análisis del comunicado de prensa en solidaridad con Rodolfo Puiggrós. Salud Colectiva, Lanus: UNLA, n. 3, p. 315-322, 2012.

RENUNCIÓ el decano de Derecho. La Nación, Buenos Aires, 10 sept. 1974.

¿RENUNCIÓ Solano Lima? Noticias, Buenos Aires, 2 jul. 1974.

REPORTAJE al compañero Juan Muciaccia (Secretario General de la J.P. de la R.A.). El Caudillo, Buenos Aires, n. 5, 14 dic. 1973.

SARLO, Beatriz. La batallas de las ideas. Buenos Aires: Ariel, 2001.

SE ACEPTA la renuncia de Puiggrós. La Razón, Buenos Aires, 2 oct. 1973.

SEÑALÓ Ottalagano los objetivos de su gestión. La Nación, Buenos Aires, 4 oct. 1974.

SERVETTO, Alicia. 73/76 el gobierno peronista contra las "provincias montoneras”. Buenos Aires: Siglo XXI, 2010.

SOLIDARIDAD con Puiggrós. La Opinión, Buenos Aires, 5 sept. 1974. 
SONDERÉGUER, María (comp.). Revista Crisis 1973-1976: del intelectual comprometido al intelectual revolucionario. Bernal: UNQUI, 2011.

TALENTO y Ventura fueron alojados en Villa Devoto. La Opinión, Buenos Aires, 23 nov. 1974g.

TRIUNFÓ la Universidad Peronista. El Descamisado, Buenos Aires, n. 21, 9 oct. 1973.

TORTTI, María Cristina (dir.). La nueva izquierda argentina (1955-1976). Rosario: Prohistoria, 2014.

TORTTI, María Cristina. El viejo partido socialista y los orígenes de la nueva izquierda. Buenos Aires: Prometeo, 2009.

U.B.A. Ciencia Nueva, Buenos Aires, n. 27, oct. 1973.

UBA. Resolución Consejo Superior, n. 12, Buenos Aires, 8 jun. 1973a.

UBA. Resolución Consejo Superior, n. 18, Buenos Aires, 8 jun. 1973 b.

UBA. Resolución Consejo Superior, n. 17, Buenos Aires, 14 jun. 1973c.

UBA. Resolución Consejo Superior, n. 29, Buenos Aires, 15 jun. 1973d.

UBA. Resolución Consejo Superior, n. 89, Buenos Aires, 17 jul. 1973 e.

UBA. Resolución Consejo Superior, n. 92, Buenos Aires, 17 jul.1973f.

UBA. Resolución Consejo Superior, n. 87, Buenos Aires, 18 jul. 1973 g.

UBA. Resolución Consejo Superior, n. 132, Buenos Aires, 26 jul. 1973h.

UBA. Resolución Consejo Superior, n. 629, Buenos Aires, 9 oct. $1973 i$.

UBA. Resolución Consejo Superior, n. 704 y 705, Buenos Aires, 10 sept. 1974.

UNIVERSIDAD: el proyecto de la CNU y Universidad: la posición del Consejo Superior. Las Bases, Órgano oficial del Movimiento Nacional Justicialista, Buenos Aires, n. 78, 22 enero 1974.

VI CONGRESO Nacional de la C.G.U. Las Bases, Órgano oficial del Movimiento Nacional Justicialista, Buenos Aires, n. 72, 12 dic. 1973e. 


\section{Referencias complementare}

BARLETTA, Ana María; LENCI, María Laura. Politización de las ciencias sociales en Argentina. El caso de la revista Antropología 3er. Mundo. Sociohistórica, UNLP, n. 8, 2000.

BARLETTA, Ana María y TORTTI, María Cristina. Desperonización y peronización en la universidad en los comienzos de la partidización de la vida universitaria. In: KROTSCH, Pedro (coord.). La universidad cautiva: legados, marcas y horizontes. La Plata: Ed. al Margen, 2002.

BURGOS, Raúl. Los gramscianos argentinos. Buenos Aires: Siglo Veintiuno Editores, 2004.

CALIFA, Juan Sebastián. El peronismo en la UBA durante la Rev. Argentina. In: Jornadas Jóvenes Investigadores, 8., 2015, Buenos Aires. Anais [...]. Buenos Aires: Instituto Gino Germani; UBA, Facultad de Ciencias Sociales, 2015.

CHAMA, Mauricio Chama; GONZÁLEZ CANOSA, Mora. Universidad, política y movimiento estudiantil: la Intervención de Kestelboim y el rol de la Juventud Universitaria Peronista en la Facultad de Derecho de la UBA. Conflicto Social, Buenos Aires: UBA, n. 5, 2011.

DE RIZ, Liliana. La política en suspenso: 1966-1976. Buenos Aires: Paidós, 2000.

DIP, Nicolás. Antecedentes y orígenes de las primeras experiencias de peronización en la UBA 1966-1970. Folia Histórica del Nordeste, n. 29, 2017b.

DIP, Nicolás. El peronismo universitario en un mundo de tensiones. Una aproximación al itinerario de las organizaciones de estudiantes y docentes peronistas de los años sesenta a través del estudio del proyecto de Universidad Nacional-Popular propuesto en la revista Envido. Nuevo Mundo, Mundos Nuevos, Cuestiones del Tiempo Presente, 2013.

DIP, Nicolás. En busca de un relato para la universidad. Reminiscencias reformistas y peronistas en Antropología 3er. Mundo. E L@tina. Revista electrónica de estudios latinoamericanos, UBA, n. 56, 2016.

DIP, Nicolás. La cuestión universitaria en debate. Antropología 3er. Mundo, cuerpos de delegados y centros de estudiantes 1968-1972. Conflicto Social. Revista del Programa de Investigaciones sobre Conflicto Social - Instituto de Investigaciones Gino Germani, n. 23, 2020.

DIP, Nicolás. La peronización de universitarios en los años sesenta y setenta. Folia Histórica del Nordeste, n. 29, 2017c. 
DIP, Nicolás. Libros y alpargatas. La peronización de estudiantes, docentes e intelectuales de la UBA (1966-1974). Rosario: Prohistoria Ediciones, 2018.

DIP, Nicolás. Libros y Alpargatas. Las tramas discursivas y organizativas del proceso de peronización de estudiantes, docentes e intelectuales de la UBA 1966-1974. Tesis de doctorado, Facultad de Humanidades y Ciencias de la Educación, Universidad Nacional de La Plata, 2017a.

DIP, Nicolás. Peronismo y Universidad en los años sesenta. Una aproximación a las tramas discursivas y organizativas del proceso de peronización de los sectores estudiantiles y docentes de la UBA (1966-1973). Cuestiones de Sociología, UNLP, n. 8, 2012.

DIP, Nicolás. Un proyecto para la universidad. De la revista Envido a la JUP y ADUP 1972-1973. Historia de la Educación. Anuario, V. 18, n. 2, 2017d.

FRIEDEMANN, Sergio. La Universidad Nacional y Popular de Buenos Aires (19731974). Una reforma universitaria inconclusa. 2015. Tesis (Doctorado en Ciencias Sociales) - Facultad de Ciencias Sociales, Universidad de Buenos Aires, Buenos Aires, 2015.

GIL, Gastón. Universidad y utopía. Ciencias sociales y militancia en la Argentina de los 60 y 70. Mar del Plata: EUDEM, 2010.

GILLESPIE, Richard. Soldados de Perón: historia crítica sobre los Montoneros. Buenos Aires: Sudamericana, 2008.

GONZÁLEZ CANOSA, Mora. Las organizaciones armadas peronistas (OAP): un análisis comparativo de los (re) posicionamientos de las FAR. In: TORTTI, María Cristina (dir.). La nueva izquierda argentina (1955-1976): socialismo, peronismo y revolución. Rosario: Prohistoria Ediciones, 2014.

LANUSSE, Lucas. Montoneros: el mito de sus 12 fundadores. Buenos Aires: vergara, 2007.

LENCI, Laura. Cámpora al Gobierno, Perón al Poder. La Tendencia revolucionaria del peronismo antes de las elecciones del 11 de marzo de 1973. In: PUCCIARELLI, Alfredo (ed.). La primacía de la política: Lanusse, Perón y la Nueva izquierda en tiempos del GAN. Buenos Aires: Eudeba, 1999.

MILLÁN, Mariano. Entre la universidad y la política. Los movimientos estudiantiles de Corrientes y Resistencia, Rosario, Córdoba y Tucumán durante la Rev. Argentina (1966-1973). 2013. Tesis (Doctorado en Ciencias Sociales) - Facultad de Ciencias Sociales, Universidad de Buenos Aires, Buenos Aires, 2013. 
MILLÁN, Mariano. Reforma, revolución y contrarrevolución. El movimiento estudiantil argentino entre laica o libre y la misión ivanissevich, 1956-1974. Escripta, UAS, v. 1, n. 1, 2019.

PÉREZ LINDO, Augusto. Universidad, política y sociedad. Buenos Aires: Eudeba, 1985.

PUIGGRÓS, Adriana. Nacionalismo popular y universidad en la Argentina de 1973-74. In: PUIGGRÓS, Adriana. Democracia y autoritarismo en la pedagogía argentina y latinoamericana. Buenos Aires: Galerna, 1991.

RUBINICH, Lucas. La modernización cultural y la irrupción de la sociología. In: JAMES, Daniel (comp.). Violencia, proscripción y autoritarismo (1944-1976). Buenos Aires:

Sudamericana, 2003.

SUASNÁBAR, Claudio. Universidad e intelectuales. Educación y política en la Argentina (1955-1976). Buenos Aires: Manantial, 2004.

SVAMPA, Maristella. El populismo imposible y sus actores, 1973-1976. In: JAMES, Daniel (comp.). Violencia, proscripción y autoritarismo (1944-1976). Buenos Aires: Sudamericana, 2003.

TORIBIO, Daniel. La universidad en la Argentina: miradas sobre su evolución y perspectivas. Buenos Aires: UNLA, 2010. 